\title{
Damping properties of non-conductive composite materials for applications in power transmission pylons
}

\author{
Kliem, Mathias; Rüppel, Marvin ; Høgsberg, Jan; Berggreen, Christian; Baier, Sina
}

Published in:

Journal of Composite Materials

Link to article, DOI:

$10.1177 / 0021998318766635$

Publication date:

2018

Document Version

Peer reviewed version

Link back to DTU Orbit

Citation (APA):

Kliem, M., Rüppel, M., Høgsberg, J., Berggreen, C., \& Baier, S. (2018). Damping properties of non-conductive composite materials for applications in power transmission pylons. Journal of Composite Materials, 52(26), 3601-3619. https://doi.org/10.1177/0021998318766635

\section{General rights}

Copyright and moral rights for the publications made accessible in the public portal are retained by the authors and/or other copyright owners and it is a condition of accessing publications that users recognise and abide by the legal requirements associated with these rights.

- Users may download and print one copy of any publication from the public portal for the purpose of private study or research.

- You may not further distribute the material or use it for any profit-making activity or commercial gain

- You may freely distribute the URL identifying the publication in the public portal 


\title{
Damping properties of non-conductive composite materials for applications in power transmission pylons
}

\author{
Mathias Kliem $^{1}$, Marvin Rüppel ${ }^{2}$, Jan Høgsberg ${ }^{1}$, Christian Berggreen $^{1}$, Sina Baier ${ }^{3}$
}

\begin{abstract}
This study aims to characterize the fibre direction dependent damping properties of non-conductive composite materials to be used in newly designed electrical power transmission pylons, on which the conducting cables will be directly connected. Thus, the composite structure can be designed both to insulate and to act as a damper to avoid for example conductor line galloping. In order to predict the damping of the composite materials, a comprehensive analysis on a representative unidirectional laminate was carried out. The fibre direction dependent damping analysis of glass and aramid reinforced epoxy and vinylester, partly reinforced with nanoclay or fibre-hybridized, was investigated using a Dynamic Mechanical Thermal Analysis and a Vibrating Beam Testing procedure for five different fibre orientations $\left(0^{\circ}\right.$, $30^{\circ}, 45^{\circ}, 60^{\circ}$ and $\left.90^{\circ}\right)$. The focus was on damping behaviour evaluation at low temperatures $\left(-20^{\circ} \mathrm{C}\right.$ and $\left.0^{\circ} \mathrm{C}\right)$ and low vibration frequencies $(0.5 \mathrm{~Hz}, 1 \mathrm{~Hz}$ and $2 \mathrm{~Hz})$, in order to represent the environmental conditions of vibrating conductor lines during. The prediction of the damping behaviour for coupon-level-specimens with three balanced laminates was successfully carried out with a maximal deviation of maximal $12.1 \%$.
\end{abstract}

\section{Keywords}

Composite materials, Damping, Nanoclay, Modal strain energy approach

\section{Introduction}

The European Network of Transmission System Operators for Electricity (ENTSOE) foresees a need for over $50.000 \mathrm{~km}$ of new or overhauled extra high voltage routes in the coming 10 years - with more than half $(28.400 \mathrm{~km})$ as new overhead lines. ${ }^{1}$ Instead of erecting new standard steel lattice towers, which were developed over 70 years ago without regard to visual appearance, new materials could enable innovative visual expressions and at the same time - through the integration of insulators in the pylon design - reduce the size of the pylons significantly. Using nonconductive raw material components in power pylons would enable the transmission lines to be attached directly to the cross arms of such a composite power pylon. The dynamic interaction between power pylon and transmission lines would however be significantly increased compared to the classic design with long insulators. Consequently, windinduced vibrations and motion of the transmission lines would then be transferred directly into the composite mast structure. As the self-damping capability of the transmission lines is limited ${ }^{2-4}$, the amplitude level associated with cable vibration phenomena, such as the severe galloping instability, is one of the main design drivers for the overall architecture of large transmission line systems. The long-wave galloping vibration is characterized by very low frequencies of $0.1-1 \mathrm{~Hz}$ and temperatures below $0{ }^{\circ} \mathrm{C} .{ }^{5,6}$ Non-symmetrical ice aggregations along the overhead transmission lines in combination with wind speeds between 4 and $20 \mathrm{~m} / \mathrm{s}^{7,8}$ can initiate self-excitation which may lead to catastrophic failure of the entire structure due to excessive vibration amplitudes at resonance. ${ }^{9,10}$ This issue can be mitigated by increasing the energy dissipation in the material used in the power pylon. The structure would act as a damper itself and thereby reduce the galloping induced vibration amplitudes of the transmission lines. The

\footnotetext{
${ }^{1}$ Department of Mechanical Engineering, Technical University of Denmark, Kongens Lyngby, Denmark

${ }^{2}$ Institut für Kunststofftechnik, Hochschule für Technik, Windisch, Schweiz

${ }^{3} 3 \mathrm{D}$ Imaging Centre, Technical University of Denmark, Kongens Lyngby, Denmark
}

Corresponding author:

Mathias Kliem, Department of Mechanical Engineering, Technical University of Denmark, Anker Engelunds Vej 1, 2800 Kongens Lyngby, Denmark

Email: mkliem@mek.dtu.dk 
damping of composite materials can be up to several orders of magnitudes higher compared to traditional engineering materials, such as metals and alloys ${ }^{11}$ and mainly depend on the orientation of the fibre reinforcement, the fibre content, the layup of the laminate and the composition of the materials involved. ${ }^{12}$ For example, a supplemental nanoclay (NC) modification of the matrix component was shown to enhance specific material properties of different matrix systems like the dielectric properties, the Young's modulus and the damping. ${ }^{13}$ Due to the large aspect ratio of the nanoclay, defined by the ratio of surface to volume, the enhanced interaction between the clay surface and the matrix results in a significant improvement of some physicochemical properties. ${ }^{14,15}$ In particular, the damping performance of composite materials in the matrixdominated off-axis directions may be enhanced by a well dispersed nanoclay. The dispersion technique thereby plays a significant role. ${ }^{16}$ Further, a composition of fibre types with different properties such as glass fibre (GF) and aramid fibre (AF) may also be used as hybrid composites to improve the damping properties of laminates. ${ }^{17}$ Although a number of studies exist in the literature regarding the dynamic mechanical characterisation of $\mathrm{NC}$ modified or neat composite materials, most publications focus on environmental conditions that are not representative for cable galloping or material compositions not suitable for the use in high-voltage power transmission pylons. The direction dependent damping of glass fibre reinforced polymers (GFRP) for unidirectional (UD) and woven laminates has been investigated only in the frequency domain from $50 \mathrm{~Hz}$ to $600 \mathrm{~Hz}^{18}$ In a preliminary work the effect of temperature on the damping behaviour was studied in the range of $20^{\circ} \mathrm{C}$ to $100^{\circ} \mathrm{C} .{ }^{19}$ The natural frequency variation of flat composite beams made of woven Kevlar and polyethylene reinforcement has been evaluated at low and high temperatures. ${ }^{20}$ To the best knowledge of the authors, only two investigations have focused on the damping performance of glass fibre reinforced plastics (GFRP) and aramid fibre reinforced plastics (AFRP) at temperatures and frequencies close to galloping environmental conditions, however excluding the off-axis damping characterisation with fibre angles $\varphi$ between $0^{\circ}$ and $90^{\circ}$, which are relevant to compute the shear damping loss factor $\eta_{12} \cdot{ }^{21,49}$ The material damping properties $\eta_{11}$ (longitudinal), $\eta_{22}$ (transverse) and $\eta_{12}$ (shear) fully describe the damping behaviour of a UD composite layer and are therefore input parameters for subsequent analytical and numerical damping analysis of multilayer structures. ${ }^{22}$ Given the damping properties of the matrix and fibre, the direction dependent material damping coefficients can be obtained by the classical rule of mixture. ${ }^{24,25}$ However, as the obtained results following this method were too inaccurate in comparison to the experimental test data, this approach will no further be discussed in this paper.

To the best knowledge of the authors, a thorough investigation on the damping performance of non-conductive composite materials at temperatures below $0^{\circ} \mathrm{C}$ and frequencies around $1 \mathrm{~Hz}$ has not been addressed in the literature so far. Thus, this study focuses on using nonconductive and NC modified composite materials with reasonable damping properties such as GFRP and AFRP as structural material in high-voltage power transmission pylons. A comprehensive damping analysis has been conducted under galloping-like environmental conditions for the materials mentioned above. The commonly used Dynamic Mechanical Thermal Analyser (DMTA) as well as the Vibrating Beam Test (VBT) have been used to determine the fibre direction dependent damping properties. ${ }^{26-29}$ Specimens with unbalanced off-axis stacking sequences, commonly used for the damping characterisation of representative UD layers ${ }^{30,31}$, lead to additional damping due to bend-twist coupling effects caused by the unbalanced layup for fibre angles $0^{\circ}<\varphi<90^{\circ}$ compared to balanced layups. ${ }^{36}$

In order to quantify the unwanted damping-side-effect for the off-axis specimens, a balanced layup configuration for all GFRP specimens has also been included in the test regime. The fibre direction dependent damping properties $\eta_{11}, \eta_{22}$ and $\eta_{12}$ of a representative UD layer made of NC modified and neat GFRP and AFRP have been calculated by the approximate Adams-Bacon method. ${ }^{31,37}$ Furthermore, a comprehensive analysis on the parameters effecting the fibre direction dependent damping such as temperature, frequency, change in matrix or fibre materials, NC modification, test method and stacking sequence has been conducted. Finally, a numerical damping prediction of bidirectional hybrid laminates has been carried out based on experimentally obtained damping properties of representative UD layers.

\section{Methods}

The fibre direction dependent damping behaviour of nonconductive composite materials was analyzed under low temperature and low frequency conditions. The calculation of damping coefficients is based on the approximate AdamsBacon damping model. ${ }^{37}$ Furthermore, the results are used 
as input parameters for the numerical damping analysis with a modal strain energy approach.

\section{Mechanical properties}

In this study, the dynamic material properties like stiffness and damping were analysed. The complex dynamic stiffness moduli $E^{*}$ and $G^{*}$ of viscoelastic materials such as composite materials contain a real part (storage moduli) $E^{\prime}$ and $G^{\prime}$ and an imaginary part (loss moduli) $E^{\prime \prime}$ and $G^{\prime \prime}$, respectively, representing the elastic and viscous effects,

$$
E^{*}=E^{\prime}+i E^{\prime \prime}, \quad G^{*}=G^{\prime}+i G^{\prime \prime} .
$$

The storage moduli of fibre reinforced plastics (FRP) are assumed to be sufficiently close to the stiffness measurements obtained under quasi-static test conditions at room temperature (RT). ${ }^{23,38}$ The stiffness has therefore been characterised by tensile tests. ${ }^{39,40}$ The damping properties were analysed by the DMTA (see section 'Dynamic mechanical thermal analysis'). A thin UD-layer may be approximated with transversal isotropy which uses five independent material properties $E_{1}^{\prime}, E_{2}^{\prime} \approx E_{3}^{\prime}, G_{12}^{\prime} \approx G_{13}^{\prime}$, $G_{23}^{\prime}, \nu_{12} \approx \nu_{13} .{ }^{41}$ The resulting stiffness properties $\left(E_{x}^{\prime}\right.$, $\left.E_{y}^{\prime}, G_{x y}^{\prime}, G_{y z}^{\prime}, \nu_{x y}\right)$ may be related to the on-axis material properties $\left(E_{1}^{\prime}, E_{2}^{\prime}, G_{12}^{\prime}, G_{23}^{\prime}, \nu_{12}\right)$ by loading a lamina in its non-principal off-axis directions $\varphi$, according to Fig. 1.

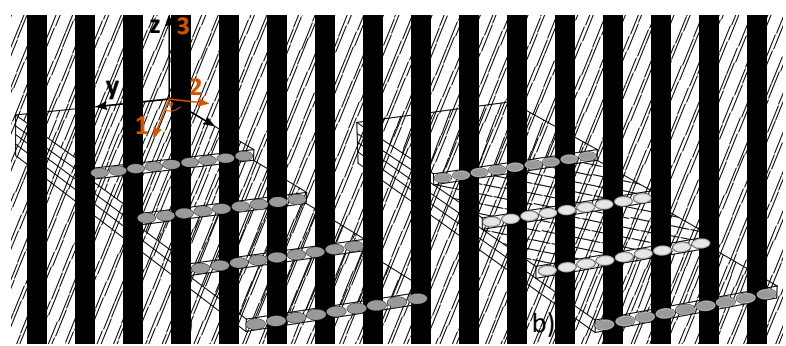

Figure 1. Relation between off-axis and on-axis coordinate systems for unbalanced (a) and balanced laminates (b).

The in-plane material properties $E_{1}^{\prime}, E_{2}^{\prime}$ and $G_{12}^{\prime}$ may therefore be calculated by

$$
\begin{aligned}
\bar{S}_{11}=\frac{1}{E_{\varphi}^{\prime}}= & \frac{1}{E_{1}^{\prime}}(\cos \varphi)^{4}\left(\frac{1}{G_{12}^{\prime}}-\frac{2 \nu_{12}}{E_{1}^{\prime}}\right) . \\
& (\sin \varphi)^{2}(\cos \varphi)^{2}+\frac{1}{E_{2}^{\prime}}(\sin \varphi)^{4}
\end{aligned}
$$

based on the experimental analysis of the poisson ratio $\nu_{12}$ and the tensile properties $E_{\varphi}^{\prime}$ of UD specimens with five different fibre orientations $\varphi=0^{\circ}, 30^{\circ}, 45^{\circ}, 60^{\circ}$ and $90^{\circ} .{ }^{31,42}$ The method of least squares has been used in order to minimise the error between the measured stiffness $E_{\varphi \exp }^{\prime}$ and the calculated stiffness $E_{\varphi}^{\prime}$

$$
\min _{\vec{x}} \sum_{j=1}^{n}\left(E_{\varphi j \text { exp }}^{\prime}-E_{\varphi j}^{\prime}(\vec{x})\right)^{2}
$$

with $\vec{x}=\left[E_{1}^{\prime}, E_{2}^{\prime}, G_{12}^{\prime}\right]$ and $n \geq 3$.

The remaining out-of-plane property $G_{23}^{\prime}$ may be approximated by the equivalent in-plane property $G_{13}^{\prime} \cdot{ }^{29,43,44}$

\section{Damping approximation}

The loss factor $\eta$ is a convenient and general damping measurement index often used in material testing or evaluation of composite materials. ${ }^{45}$ At low damping levels, the loss factor $\eta$ is related to other damping definitions by

$$
\eta \approx \frac{\psi}{2 \pi} \approx \frac{\lambda}{\pi} \approx 2 \zeta \approx \tan \delta \approx \delta
$$

with $\psi, \lambda, \zeta$ and $\delta$ being the specific damping capacity, the logarithmic decrement, the damping ratio and the phase angle, respectively. ${ }^{46}$ The damping behaviour of UD composite laminates depends as far the static mechanical properties discussed above, on the fibre direction and may be approximated by the Adam-Bacon-approach, ${ }^{31,37}$

$$
\begin{gathered}
\eta_{\varphi}=E^{\prime}(\varphi)\left[\frac{\eta_{1}}{E_{1}^{\prime}}(\cos \varphi)^{4}+\frac{\eta_{2}}{E_{2}^{\prime}}(\sin \varphi)^{4}+\right. \\
\left.\left(\frac{\eta_{12}}{G_{12}^{\prime}}-\left(\eta_{1}+\eta_{2}\right) \frac{\nu_{12}}{E_{1}^{\prime}}\right)(\sin \varphi)^{2}(\cos \varphi)^{2}\right] .
\end{gathered}
$$

This assumption is only valid in the 'free flexure' condition: In case a beam is subjected to pure bending, the resulting twist due to bend-twist-coupling is allowed. The direction dependent in-plane damping properties $\eta_{11}$, $\eta_{22}$ and $\eta_{12}$ are based on the experimentally obtained damping properties $\eta_{\varphi}$ of UD specimens with different fibre orientations $\varphi=0^{\circ}, 30^{\circ}, 45^{\circ}, 60^{\circ}$ and $90^{\circ}$ and are therefore only valid for the specific temperature and frequency conditions used for the experimental testing. The error between the measured damping $\eta_{\varphi \exp }$ and the calculated damping $\eta_{\varphi}$ has again been minimised by using the method of least squares,

$$
\begin{array}{r}
\min _{\vec{x}} \sum_{j=1}^{n}\left(\eta_{\varphi j} \exp -\eta_{\varphi j}(\vec{x})\right)^{2} \\
\text { with } \vec{x}=\left[\eta_{1}, \eta_{2}, \eta_{12}\right] \text { and } n \geq 3 .
\end{array}
$$

The out-of-plane damping properties for thin walled structures were approximated by the in-plane equivalents: $\eta_{22} \approx \eta_{33}, \eta_{12} \approx \eta_{13} \approx \eta_{23} .{ }^{23}$ These fibre direction dependent material damping properties have been used as input 
parameters for the numerical damping analysis described in the following.

\section{Numerical damping analysis by modal strain energy method}

The implementation of structural damping in commercially available finite element (FE) software is usually provided by mass and stiffness proportional coefficients in what is known as Rayleigh damping. ${ }^{47}$ Since the proportional damping is not suitable to model the orthotropic material damping in composites, the modal strain energy approach is used in the numerical damping analysis. ${ }^{48}$ The loss factor $\eta$ may be calculated by

$$
\eta=\frac{1}{2 \pi} \frac{\Delta U}{U}
$$

where $\Delta U$ represents the dissipated energy during a single oscillation, while $U$ is the maximum strain energy stored within that cycle. ${ }^{49}$ The strain energy approach may manually be integrated into a commercially available FEcode in order to analyse the modal damping of a multilayer composite structures. The dissipated energy and the strain energy may be computed separately for the $m$-th finite element in the $k$-th UD-layer used in the numerical model (see Eq. 10). However, the contribution of these energies are direction dependent due to the orthotropic nature of composite material. Therefore, the direction dependency needs to be taken into account by considering the tensor components in all directions $(i, j=1,2,3)^{22,23}$ by

$$
U_{i j}^{[m]}=\frac{1}{2} \sigma_{i j}^{[m]} \epsilon_{i j}^{[m]} V^{[m]},
$$

where $\sigma_{i j}^{[m]}, \epsilon_{i j}^{[m]}$ and $V^{[m]}$ are the direction dependent stress and strain components within the volume of the $m$-th element. The equivalent dissipated energy for the $m$-th finite element may then be obtained by

$$
\Delta U_{i j}^{[m]}=\eta_{i j} U_{i j}^{[m]}
$$

where $\eta_{i j}$ are the experimentally obtained fibre direction dependent material damping properties, required as input parameters. The modal loss factor of the structure for the $n$-th mode may then be calculated by

$$
\eta_{n}=\frac{\sum_{m=1}^{N_{e}} \sum_{k=1}^{N} \sum_{i=1}^{3} \sum_{j=1}^{3}\left(\Delta U_{i j}^{[m](k)}\right)_{n}}{\sum_{m=1}^{N_{e}} \sum_{k=1}^{N} \sum_{i=1}^{3} \sum_{j=1}^{3}\left(U_{i j}^{[m](k)}\right)_{n}},
$$

where $N_{e}$ and $N$ represent the total number of finite elements and the number of layers, respectively. The numerical damping analysis based on a representative UD-layer was carried out using the commercial FEM software ABAQUS. The relevant material properties assuming a plane stress state are $\mathrm{E}_{1}, \mathrm{E}_{2}, \mathrm{G}_{12}$ and $\nu_{12}$, as shown in Eq. (2) and later in Tab. 3. The development of an integrated PYTHON code enables the calculation and plotting of the modal damping $\eta_{n}$ at the end of any finite element analysis (FEA) in order to provide a continuous simulation within ABAQUS, thereby avoiding additional post-processing steps.

The aim of the numerical simulation is to model and verify the experimental VBT investigation, in order to predict the first natural frequency $f_{1}$ and the related modal damping $\eta$ of a vibrating cantilever composite beam made of GF-EP-0 with the symmetric and balanced stacking sequence $[+\varphi$, $-\varphi]_{s}$, composed of representative UD-layers. The sample dimensions are listed in Tab. 1 and the static material properties of the representative UD-layer are shown in Tab. 3. The density of GF-EP and GF-VE has been calculated with $\rho=1.79 \mathrm{~g} / \mathrm{cm}^{3}$ and $\rho=1.77 \mathrm{~g} / \mathrm{cm}^{3}$, assuming a fibrevolume-ratio (FVR) $\mathrm{V}_{f}=0.5$. The modal loss factors $\eta_{11}$, $\eta_{12}$ and $\eta_{22}$ are used as input parameter in order to calculate the modal damping of the vibrating composite beam. Four different input parameter configurations are used to simulate the VBT analysis, based on varying stacking sequences and test methods: 1. - unbalanced, DMTA | 2. - balanced, DMTA | 3. - unbalanced, VBT | 4.- balanced, VBT (see Section 'Effect of stacking sequence'). A mesh of fully integrated, 8-node C3D8I hexahedron elements was created to model the vibrating beam in ABAQUS. This element type provides internally added incompatible deformation modes and is therefore a cost effective way to model the bending behaviour of structures, even with only one element through the thickness. ${ }^{33-35}$ The composite interface in Abaqus was used to assign the laminate stack and its orientation to the mesh. Selected degrees-of-freedom at the root-end section of the beam were constrained in order to realize the clamped boundary condition of the subsequent experiments.

\section{Experimental investigation}

This section provides a detailed description about the materials, methods and procedures used to analyse the fibre direction dependent damping of GFRP and AFRP at low temperatures and low frequencies. Furthermore, the quality and the uniformity of the different laminates were investigated by comparing FVR and images from the computerized axial tomography (CT). The two common 
measurement methods for damping characterisation, DMTA and VBT, were used to evaluate the effect of different material and testing parameters on the loss factor $\eta$, e.g. matrix material, fibre material, temperature and frequency. The experimental set-ups as well as the testing procedures are described in this section. The data sets of all test results are published separately and freely available. ${ }^{50}$

\section{Materials and sample preparation}

Two widely used resin systems, a Bisphenol-Epoxy Vinyl Ester Resin DION IMPACT 9102-683 (VE) and an Epoxy Infusion System PRIME 20LV (EP) as well as their nanoclay modified equivalents, have been used as matrix systems. The nanoclay modification of these resin systems was successfully carried out and evaluated by material testing and microscopic examination in a previous work. ${ }^{13}$ The NC Garamite 1958 was thereby dispersed into the neat VE and EP with different weight \% (wt. \%) using a highspeed homogeniser. An extensive morphology analysis of the nanocomposites using scanning electron microscopy (SEM), transmission electron microscopy (TEM), X-ray diffraction (XRD) and rheology analysis was conducted to evaluate the level of exfoliation. Furthermore, the static and dynamic mechanical properties of the neat VE and EP as well as their modified equivalents, treated with 2 wt. $\%$, were compared. However, the same nanoclay modified VE and EP with 2 wt. \% was used right after the dispersion process to manufacture the composite plates for dynamic testing. ${ }^{13}$ The specimens are therefore used to verify the transferability of the beneficial effect by nanoclay from polymer level to composite level. A UD GF fabric with an area weight of $475 \mathrm{~g} / \mathrm{m}^{2}$ (incl. $35 \mathrm{~g} / \mathrm{m}^{2}$ of a chopped strand mat) and a UD AF fabric with $109 \mathrm{~g} / \mathrm{m}^{2}$ (incl. $20 \mathrm{~g} / \mathrm{m}^{2}$ AF-weft at $\varphi=90^{\circ}$ ) were used. UD VE- and EP-reinforced GF- and AF-plates, with and without 2 wt. $\%$ of NC modification, were manufactured by hand-layup, followed by vacuum bagging, cured at room temperature (RT) and post-cured at $40^{\circ} \mathrm{C}$ for at least $24 \mathrm{~h}$ and then $10 \mathrm{~h}$ at $70^{\circ} \mathrm{C}$.

As already mentioned in the introduction, bend-twist coupling effects are assumed to affect the damping properties of composite laminates. ${ }^{36}$ In order to quantify the damping contribution related to these coupling effects of the symmetric, unbalanced GFRP specimens, additional bidirectional, symmetric and balanced GFRP plates were manufactured. Different specimens with regard to testing method, material, dimensions and stack were cut using waterjet for five different fibre orientations, as shown in Tab. 1. The specimens analysed with VBT were also used for quasi-static tensile tests.

\section{Quality assurance}

The fibre volume ratio is a common parameter to verify a homogeneous fibre and matrix material distribution within a composite structure. ${ }^{51}$ Three samples per plate in the size of around $80 \mathrm{~mm}$ x $20 \mathrm{~mm}$ were taken from different locations and burned at $620^{\circ} \mathrm{C}$ for $4 \mathrm{~h}$ according to the standard. ${ }^{52}$ The relative weight of the fibre $\psi$ was calculated by

$$
\psi=\frac{m_{f}}{m_{t o t}},
$$

with $\mathrm{m}_{t o t}$ and $\mathrm{m}_{f}$ representing the total weight of the specimen (before burning) and the weight of the fibre (after burning). The fibre volume ratio $\mathrm{V}_{f}$ was determined by

$$
V_{f}=\frac{1}{1+\frac{1-\psi}{\psi} \frac{\rho_{f}}{\rho_{m}}}
$$

where $\rho_{m}$ and $\rho_{f}$ are the densities of the matrix and fibre. ${ }^{53}$ The determination of the FVR by combustion is only suited for GF composite, as AF will partly burn and degrade. ${ }^{54}$ Furthermore, the CT device 'ZEISS XRadia 410 Versa' was used to generate cross-sectional images from representative GF and AF specimens, illustrating the sample quality and uniformity with respect to voids, resin rich areas and fibre undulations. The instrument was operated at $40 \mathrm{kV}$ and $60 \mathrm{kV}$ for AFRP and GFRP samples. Image acquisition was performed using the large field of view objective and 1601 projections with $4 \mathrm{~s}$ and $5 \mathrm{~s}$ exposure time for AFRP and GFRP samples. Image reconstruction was performed using the inbuilt acquisition and reconstruction software package provided by ZEISS, while for visualization the software 'Avizo9.4.0' from FEI was used.

\section{Static mechanical testing}

The static material characterisation was carried out on a servo-hydraulic MTS 312.21 test machine with an $100 \mathrm{kN}$ actuator and a $5 \mathrm{kN}$ load cell. The unbalanced and balanced tensile test specimens were quasi-statically tested at a strain rate of $0.5 \mathrm{~mm} / \mathrm{min}$, which is well below the dynamic test conditions. Hydraulic grips were used to clamp the composite samples, whereof the lower one had a rotational degree of freedom. The calculation of the tensile moduli $E_{\varphi j \exp }^{\prime}$ and the poisson ratio $\nu_{12}$ is based on the ASTM standard D3039. ${ }^{55}$ Two specimens were tested per material configuration and fibre orientation. Each specimen was released before repeating the measurement three times resulting in six measurements in total for each configuration. 
Table 1. Overview of the different specimen configurations.

\begin{tabular}{ccccc}
\hline Method & Frequency & Fibre material & Stack & Sample size $(\mathrm{L} \times \mathrm{W} \times \mathrm{T})$ \\
\hline \multirow{2}{*}{ DMTA } & $0.5-2 \mathrm{~Hz}$ & GF & {$[\varphi]_{3}$} & $60 \mathrm{~mm} \times 10 \mathrm{~mm} \times 1.5 \mathrm{~mm} \pm 0.1 \mathrm{~mm}$ \\
& & AF & {$[\varphi]_{5}$} & $60 \mathrm{~mm} \times 10 \mathrm{~mm} \times 0.9 \mathrm{~mm} \pm 0.1 \mathrm{~mm}$ \\
\hline & & GF & {$[ \pm \varphi]_{s}$} & $220 \mathrm{~mm} \times 15 \mathrm{~mm} \times 2 \mathrm{~mm} \pm 0.1 \mathrm{~mm}$ \\
VBT & $20 \mathrm{~Hz} \pm 1 \mathrm{~Hz}$ & $\mathrm{AF}|\mathrm{GF}| \mathrm{GF}|\mathrm{GF}| \mathrm{AF}$ & {$[\varphi]_{3}$} & $220 \mathrm{~mm} \times 15 \mathrm{~mm} \times 1.5 \mathrm{~mm} \pm 0.2 \mathrm{~mm}$ \\
& & GF $|\mathrm{AF}| \mathrm{GF}|\mathrm{AF}| \mathrm{GF}$ & {$[\varphi]_{5}$} & $220 \mathrm{~mm} \times 15 \mathrm{~mm} \times 1.9 \mathrm{~mm} \pm 0.1 \mathrm{~mm}$ \\
\hline
\end{tabular}

\section{Dynamic mechanical thermal analysis}

The DMTA is a widely used method to analyse the damping behaviour of fibre reinforced composites. ${ }^{56}$ The loss factor $\eta$ was measured in different fibre orientations $\varphi=0^{\circ}, 30^{\circ}$, $45^{\circ}, 60^{\circ}$ and $90^{\circ}$. The fibre direction dependent damping properties of a representative UD layer $\eta_{11}, \eta_{22}$ and $\eta_{12}$ were then calculated based on Eq. (5) and Eq. (6). A threepoint bending fixture with a span of $50 \mathrm{~mm}$ and spherical bearings, allowing rotations around the lengthwise axis of the specimens, were used to minimize clamping effects and in order to fulfil the 'free-flexure' condition required by the Adam-Bacon approach. ${ }^{37}$ As polymer materials exhibit a pronounced strain-rate dependency on the mechanical properties, a preliminary strain-rate analysis was carried out in order to determine a vibration amplitude related to the linear region of the amplitude-force-diagram, suitable for all material configurations, environmental test conditions and fibre directions. ${ }^{57}$ The results of the strain-rate analysis are demonstrated in Fig. 2 for a GF-EP-0 specimen with a $\pm 30^{\circ}$ configuration at $-20^{\circ} \mathrm{C}$ and $+20^{\circ} \mathrm{C}$, and a constant test frequency of $1 \mathrm{~Hz}$.

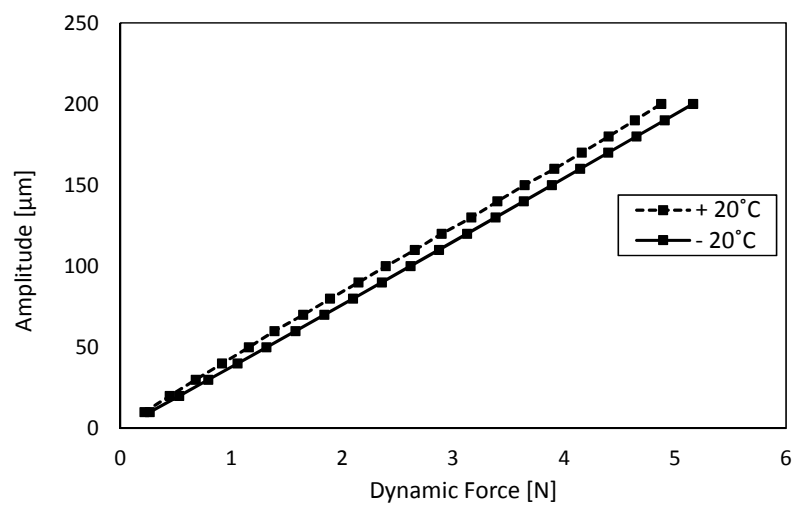

Figure 2. Strain-rate analysis of a GF-EP-0 specimen $\left[+30^{\circ}\right.$, $\left.-30^{\circ}\right]_{s}$ at $-20^{\circ} \mathrm{C}$ and $+20^{\circ} \mathrm{C}$ and $1 \mathrm{~Hz}$.

Due to the linear strain-rate behaviour, a global amplitude of $150 \mu \mathrm{m}$ was chosen for all DMTA tests. The test conditions were chosen so that they resemble those in a galloping-prone environment with frequencies between $0.5 \mathrm{~Hz}$ and $2.0 \mathrm{~Hz}$ and temperatures between $-20{ }^{\circ} \mathrm{C}$ and $0{ }^{\circ} \mathrm{C}$. ${ }^{5,6}$ Additional damping measurements were carried out with the vibrating beam test (VBT) method at $20^{\circ} \mathrm{C}$ in order to verify the comparability of the two common damping measurement techniques.

\section{Vibrating beam testing}

The VBT method is commonly used to analyse the damping properties of under-damped systems such as composite beams by analysing the free vibration decay of an oscillating structure at its first natural frequency $f_{1} \cdot{ }^{58-60}$ Different excitation techniques with various suitability for the damping evaluation have previously been used, such as the excitation by shaker ${ }^{61}$, by impact hammer ${ }^{17}$ or by initial displacement. ${ }^{62-64}$ The activation of mainly the first mode may be well achieved by an initial displacement, as the focus is on the damping characteristics at the lowest natural frequency. A free-flexural configuration of the test is required to analyse the damping based on the AdamBacon approach. ${ }^{37}$ The specifications of the test samples are listed in Tab. 1. The cantilever specimens were horizontally fixed between two clamping plates, screwed together with a tightening torque of $15 \mathrm{Nm}$. An initial tip displacement was set and released for all specimen configurations and fibre directions. By adjusting the free length of each specimen, all VBT were carried out at a constant vibration frequency $f_{1}$ around $20 \mathrm{~Hz} \pm 1 \mathrm{~Hz}$. The dynamic response of the beam was measured contact-free at a distance of $5 \mathrm{~mm}$ from the beam tip by a laser displacement sensor optoNCDT 1402 from Micro-Epsilon at a sampling frequency of $2000 \mathrm{~Hz}$, connected to the analog input module NI 9215 from National Instruments. The dynamic response of the vibrating beam is represented by a declining sine curve, on which an exponential decay curve may be fitted as an envelope. It is assumed that mainly the first mode dominates the behaviour and that any influence from other modes may be neglected. The resulting envelope $g(t)$ for the first mode may therefore be described as

$$
g(t)=X_{0} e^{-\zeta \omega_{1} t}
$$


with $\omega_{1}, \zeta$ and $X_{0}$ being the natural frequency, the damping ratio and the initial displacement, respectively. ${ }^{65}$ The loss factor is calculated based on Eq. (4). Two specimens were tested per material configuration. Each specimen was released before repeating the measurement three times (six measurements in total per material configuration and fibre direction).

\section{Results and Discussion}

The results of the static mechanical analysis are presented, followed by the results of the experimental damping analysis of relevant composite materials for the use in high-voltage power pylons. The comparability of these results is ensured by verifying the uniformity of the investigated samples with a consistent FVR and representative CT-scans. The fibre direction dependent damping properties are evaluated with regard to various test and design parameters such as different matrix materials, fibre materials, supplemental NC modification, temperature and frequency variation, as well as different test methodologies and stacking sequences. Finally, the results of the numerical damping analysis of hybrid laminates are compared to equivalent experimental results.

\section{Quality assurance}

The uniformity and internal structure of representative specimens were evaluated based on the FVR and X-ray tomograms. The FVR was analysed for all GF samples, whereas only representative GF-EP, GF-VE and AF-EP specimens were CT-scanned. The results of the relative fibre weight $\psi$ and the FVR $\mathrm{V}_{f}$ are presented in Tab. 2. The slightly higher relative fibre weight of GF-VE compared to GF-EP may be explained by a lower resin density of VE than EP. The increase of $\psi$ with the application of $\mathrm{NC}$ is due to the non-combustible nature of the NC.

A visual difference of GF samples with and without $\mathrm{NC}$ is also observed with respect to color and cohesion of the remaining fibre bundles (Fig. 3). However, the difference in
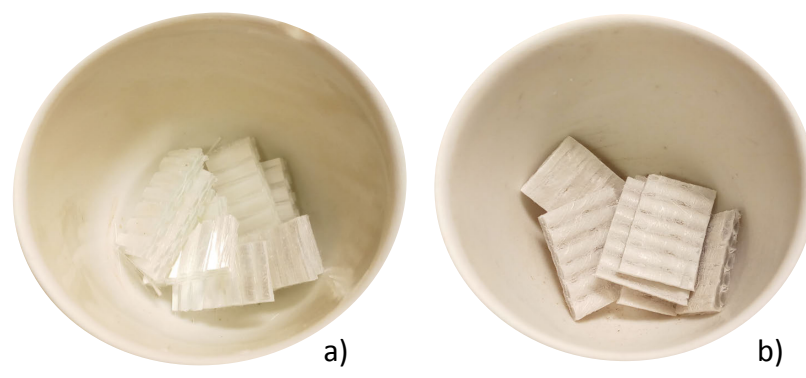

Figure 3. Raw GF without (a) and with (b) a previous NC modification of the resin before combustion. the FVR's and the related standard deviations with regard to the two groups (with NC and without NC) demonstrates a uniform matrix-fibre distribution of the GF sample plates. A comparability of the static and dynamic mechanical properties, determined by DMA and VBT (see section 'Experimental damping investigation'), is thereby ensured.

A quality assurance with regard to voids and undulations was carried out using CT-scans. X-ray tomograms of AF-EP (A), GF-VE (B) and GF-EP (C) samples were qualitatively analysed. Three representative images are presented in Fig. 4, referring to the coordinate system defined in Fig. 1.

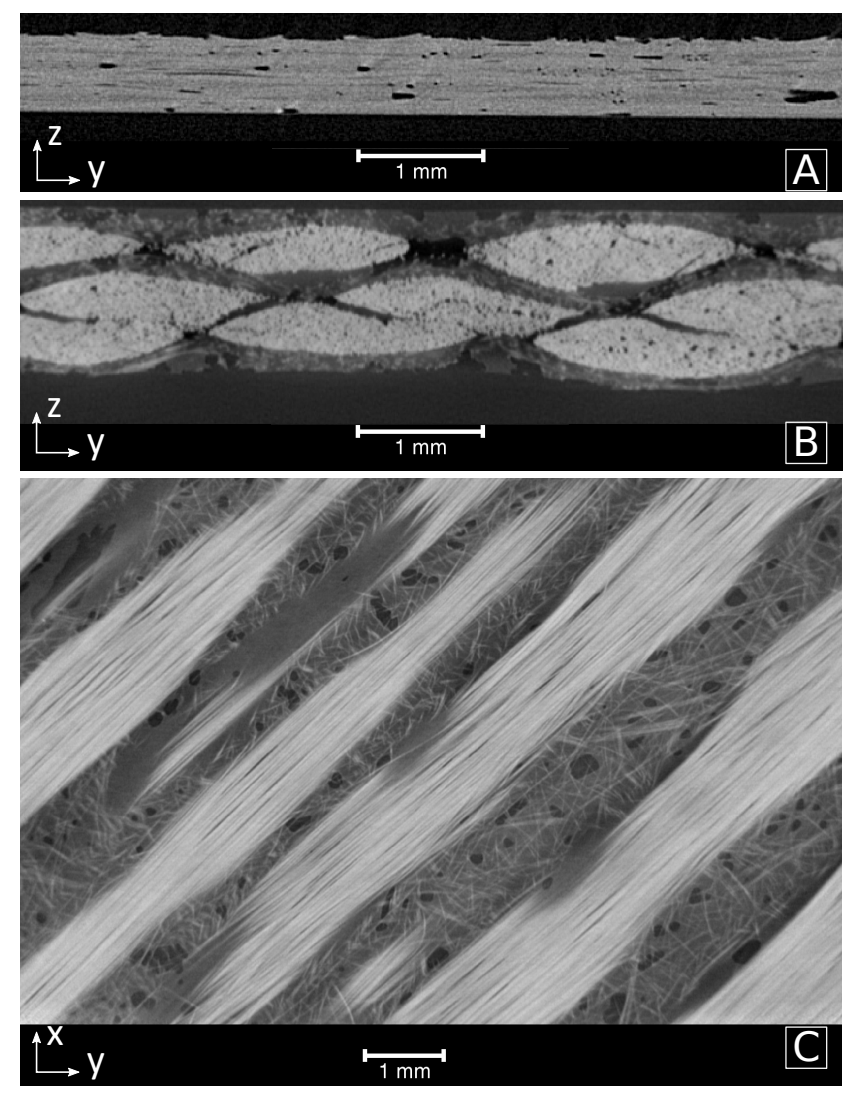

Figure 4. X-ray tomograms of AF-EP (A), GF-VE (B) and GF-EP (C)

The poor contrast of the X-ray tomogram A, representing the cross section of AF-EP, is due to similar densities of AF $\left(\rho=1.42 \mathrm{~g} / \mathrm{cm}^{3}\right)$ and $\mathrm{EP}\left(\rho=1.08 \mathrm{~g} / \mathrm{cm}^{3}\right)$. A better contrast is obtained for GF-VE (tomogram B) and GF-EP (tomogram C) due to the density of GF with $\rho=2.5 \mathrm{~g} / \mathrm{cm}^{3}$. No fibre undulations are observed in tomogram C. Instead, voids with dimensions up to $0.5 \mathrm{~mm}$ are identified within all three specimens. Its location between the fibre bundles is due to the use of fibres with a relatively low fineness of 2400 tex. Finer fibre bundles (lower tex) may lead to smaller gaps, resulting in smaller voids.

Furthermore, the manufacturing method (see section 'Materials and sample preparation') is prone to a high void content, due to the manual application of resin. As the same 
Table 2. Results of the relative fibre weights $\psi$ and the fibre-volume-ratios $\mathrm{V}_{f}$ of all GF samples determined by combustion.

\begin{tabular}{ccccc}
\hline Material & GF-0-EP & GF-2-EP & GF-0-VE & GF-2-VE \\
\hline Rel. fibre weight $\psi[\%]$ & $67.6 \pm 0.8$ & $69.0 \pm 0.4$ & $68.8 \pm 0.2$ & $70.0 \pm 0.7$ \\
\hline Fibre-volume-ratio $\mathrm{V}_{f}[\%]$ & $47.5 \pm 0.9$ & $49.1 \pm 0.5$ & $47.6 \pm 0.3$ & $49.0 \pm 0.9$ \\
\hline
\end{tabular}

manufacturing method was used for all investigated test sample plates, a similar void characteristics and distribution is assumed for all DMA and VBT specimens. Therefore, the potential effect of the voids on the damping behaviour is assumed to be equal for all investigated specimens.

\section{Static mechanical testing}

Quasi-static tensile tests were used to determine the fibre direction dependent tensile moduli $E_{\varphi i \text { exp }}^{\prime}$ for all material configurations, with and without the NC modification. The results are presented in Fig. 5 and Fig. 6 for the GF- and AFspecimens, respectively.

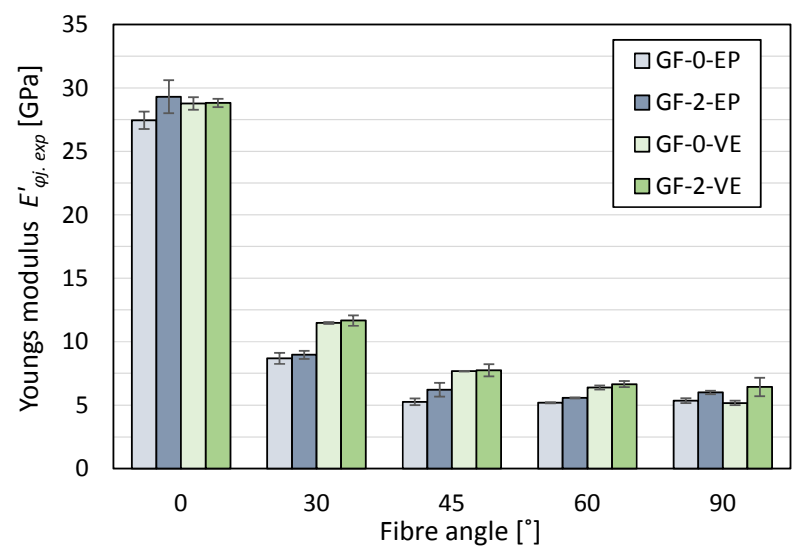

Figure 5. Fibre direction dependent Youngs modulus $E_{\varphi j \text { exp }}^{\prime}$ for GF-EP and GF-VE (unmodified and modified with 2 wt. \% $\mathrm{NC)}$

For both materials and fibre directions, the NC modification has a slight increasing effect on the Youngs modulus $E_{\varphi j \text { exp }}^{\prime}$, which is consistent with the literature. ${ }^{13}$ Independent of the $\mathrm{NC}$ content, the matrix material VE shows generally higher stiffness for all GF specimens compared to EP. This effect is not observed for the AF specimens and may be explained by a different sizing-matrix-compatibility of AF to VE and EP. ${ }^{66}$

The stiffness maximum is at $\varphi=0^{\circ}$ along the fibre direction for GF and AF specimens. The small amount of weft thread in the AF fabric leads to a stiffness increase for $\varphi=90^{\circ}$. The major drop in stiffness between $\varphi=0^{\circ}$ and $30^{\circ}$ for all AF specimens, independent of the matrix, may be explained by the anisotropic material behaviour of AF. ${ }^{67,68} \mathrm{~A}$ slight fibre misalignment will cause a significant stiffness drop,

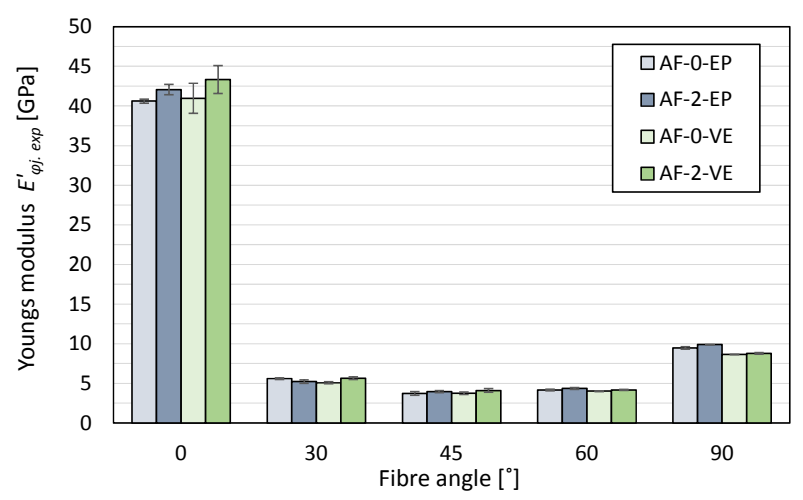

Figure 6. Fibre direction dependent Youngs modulus $E_{\varphi i \text { exp }}^{\prime}$ for AF-EP and AF-VE (unmodified and modified with 2 wt. \% $\mathrm{NC)}$

which explains the larger standard deviation for $\varphi=0^{\circ}$. A smoother stiffness drop for the same angle range is observed for GF specimens in Fig. 5. Furthermore, no reinforcing effect for $\varphi=90^{\circ}$ is observed for GF samples, as pure UD fabrics with chopped strand mats were used (see Section 'Materials and sample preparation').

The standard deviation of the fibre direction dependent tensile moduli was considered in the calculation of the material properties in its principle directions by Eq. (2) and (3). The variation is plotted in a polar diagram (see Fig. 7). The resulting material properties for a

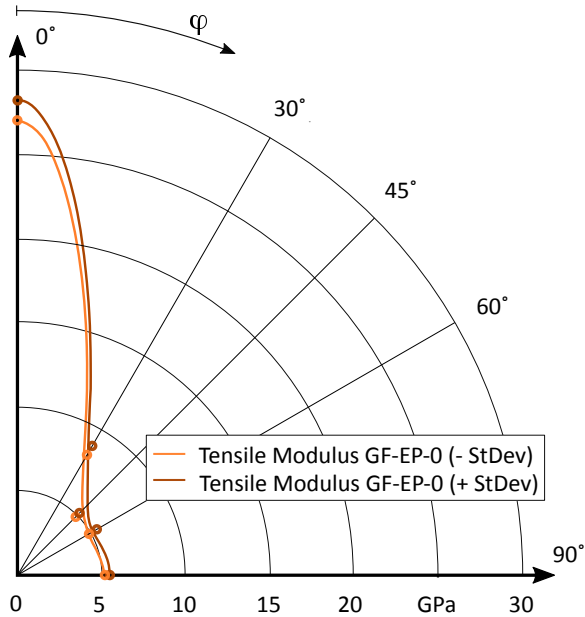

Figure 7. Variation of the fibre direction dependent off-axis tensile moduli of GF-EP-0 (input values for the optimization in Eq. (3)) with respect to its standard deviation.

representative UD-layer $E_{1}, E_{2}$ and $G_{12}$, obtained from the optimization by Eq. (3), are shown in Tab. 3 for all 


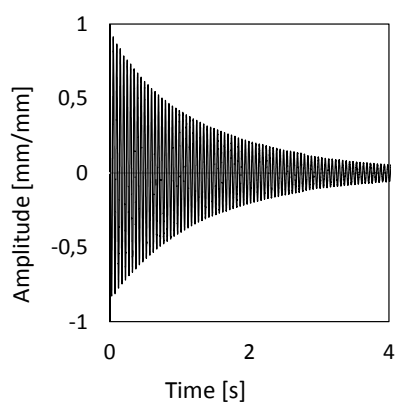

(a) Normalized free decay of a vibrating specimen.

(b) Measured data vs. exponential fit.

Figure 8. Free vibration of a GF-2-EP-60 specimen (Glass fibre | Epoxy resin | 2 wt. \% NC $\mid \varphi=60^{\circ}$ ).

GF-composite configurations. The variation represents the standard deviation of the fibre direction dependent tensile moduli.

However, the fibre direction dependent tensile moduli of unbalanced laminates only represent the apparent stiffness, due to the constrained shear-tension-coupling caused by the hydraulic grips of the test machine.

\section{Experimental damping investigation}

The effect of the matrix material, the fibre material, the $\mathrm{NC}$ modification as well as the temperature and frequency on the fibre direction damping properties were analysed in galloping-like environmental conditions by DMTA measurements. Although no standard deviation is available for the DMTA measurements, because the analysis only contains a single specimen per material configuration and fibre direction, several DMTA-internal measurements of the loss factor with necessarily consistent results were made before generating an average damping value.

The effect of a balanced and unbalanced stacking sequence on the direction dependent damping properties are analysed by VBT and DMTA at room temperature. The amplitudetime signal of the VBT measurement is assumed to be related to the first activated bending mode only and the damping ratio may therefore be estimated well by the exponential fit of Eq. (13) to the envelope of the free decay curve. The good agreement is shown in Fig. 8 for GF-EP with 2 wt. \% NC and a fibre angle of $\varphi=60^{\circ}$.

Effect of matrix material The damping properties of composite materials are highly dependent on the fibre direction. The loss factor $\eta$ of a representative UD layer in transverse direction $\left(\varphi=90^{\circ}\right)$ is generally higher compared to its longitudinal direction $\left(\varphi=0^{\circ}\right)$, represented by

$$
\eta_{90}=\left(\frac{E^{\prime \prime}}{E^{\prime}}\right)_{90}>\left(\frac{E^{\prime \prime}}{E^{\prime}}\right)_{0} .
$$

This is due to the matrix dominated properties in transverse direction and the much higher damping of the viscoelastic polymer compared to the fibre. Although the loss modulus in longitudinal direction $E_{0}^{\prime \prime}$ may be larger than $E_{90}^{\prime \prime}$ in transverse direction, the high storage modulus $E_{0}^{\prime}$ in longitudinal direction, dominated by the fibre, leads to a lower loss factor $\eta_{0}$ compared to $\eta_{90}$ (see Eq. (14). ${ }^{32}$ Thus, any change or modification with respect to the matrix material composition will mainly affect the off-axis damping properties. According to the DMTA results of GF-VE and GF-EP (measured at $0{ }^{\circ} \mathrm{C}$ and $1 \mathrm{~Hz}$ ) presented in Fig. 9, the matrix material VE shows significantly higher damping properties of about $20 \%$ to $40 \%$ for all off-axis fibre directions compared to EP.

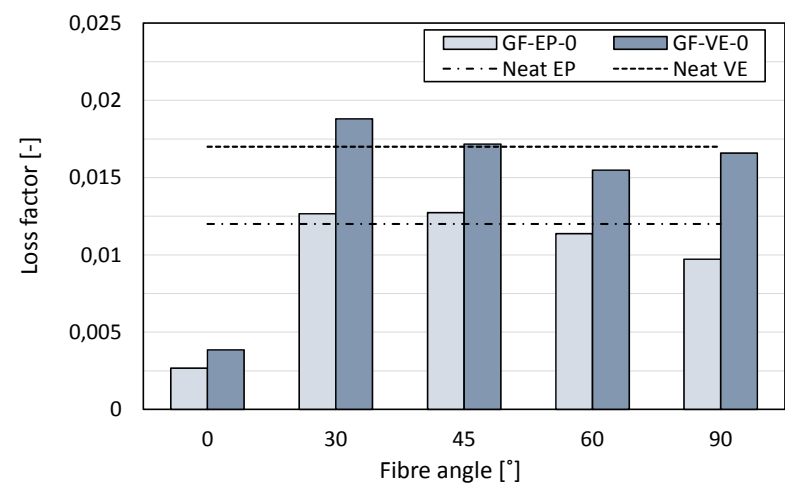

Figure 9. Effect of the matrix material VE and EP on the fibre direction dependent damping behaviour of GF-EP and GF-VE [DMTA, $0^{\circ} \mathrm{C}$ at $1 \mathrm{~Hz}$ ]

Moreover, the loss factor $\eta$ in fibre direction remains relatively unchanged for EP and VE, as the behaviour is governed by the GF. Furthermore, the off-axis damping properties of GF-VE and GF-EP represent the damping properties of neat EP with $\eta_{E P}=0.012$ and VE with $\eta_{V E}=0.017$ at $0^{\circ} \mathrm{C}$. These observations are consistent with a previous study. ${ }^{13}$ The peak damping is obtained for both materials at an off-axis fibre direction at $\varphi \approx 30^{\circ}$, since the contribution of damping due to bend-twist-coupling reaches its maximum at fibre angles $\varphi \approx 30^{\circ} .{ }^{36}$ As mentioned in section 'Damping approximation', the approach by AdamsBacon, predicting $\eta_{11}, \eta_{22}$ and $\eta_{12}$, is only valid for the 'free flexure' condition, allowing the beam to twist during bending. This condition is full filled for both the DMTA and VBT. The approach is therefore assumed to successfully predict the additional damping due to the bendtwist-coupling based on several individual measurements of the off-axis damping for various fibre directions $\varphi$. However, available data of the predicted fibre direction damping of off-axis laminates under 'free flexure' conditions ${ }^{37}$ coincides with the observed trend represented in Fig. 9. When applying 
Table 3. Material properties of a representative UD layer assuming a plane stress state.

\begin{tabular}{cccccc}
\hline Material & wt. \% NC & $\mathrm{E}_{1}{ }_{1}[\mathrm{GPa}]$ & $\mathrm{E}_{2}{ }_{2}[\mathrm{GPa}]$ & $\mathrm{G}_{12}{ }_{12}[\mathrm{GPa}]$ & $\nu_{12}$ \\
\hline \multirow{2}{*}{ GF-EP } & 0 & $27.6 \pm 0.6$ & $5.3 \pm 0.2$ & $2.0 \pm 0.1$ & $0.345 \pm 0.06$ \\
& 2 & $29.9 \pm 1.6$ & $5.8 \pm 0.2$ & $2.2 \pm 0.1$ & $0.324 \pm 0.01$ \\
GF-VE & 0 & $28.8 \pm 0.5$ & $5.3 \pm 0.8$ & $2.6 \pm 0.1$ & $0.374 \pm 0.06$ \\
& 2 & $28.8 \pm 0.3$ & $6.9 \pm 0.5$ & $2.6 \pm 0.1$ & $0.330 \pm 0.08$ \\
\hline
\end{tabular}

the modal strain energy approach based on the damping properties of the (unbalanced and symmetric) representative UD layer to a symmetric and balanced multi-layer structure, a systematic error is taken into account due to absence of the structural bend-twisting coupling effects. Therefore, a damping analysis of a symmetric and balanced representative UD layer was carried out in order to quantify the damping caused by bend-twisting effects (see Section 'Effect of stacking sequence'). Based on the results shown in Fig. 9, VE as matrix material is recommended with regard to damping enhancement.

Effect of fibre material Investigations of AF composites showed approximately two to four times higher damping properties compared to GF composites at room temperature. ${ }^{17,31}$ A similar damping behaviour has been observed for temperatures and frequencies at $-20^{\circ} \mathrm{C}$ and $1 \mathrm{~Hz}$ (see Fig. $10)$

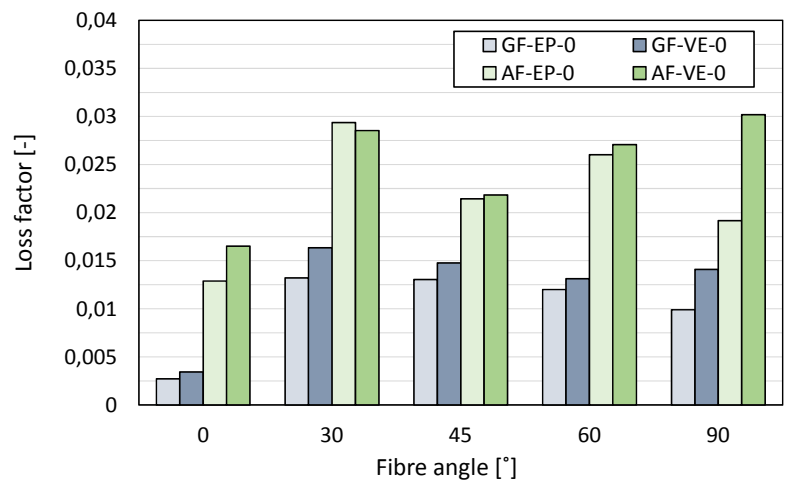

Figure 10. Effect of the fibre material GF and AF on the fibre direction dependent damping behaviour of fibre reinforced EP and VE [DMTA, $-20^{\circ} \mathrm{C}$ at $\left.1 \mathrm{~Hz}\right]$

The fibre dominated loss factor for AF composites at $\varphi=0^{\circ}$ is with $\eta_{A F_{0}} \approx 0.015$ up to 5 times larger than the equivalent GF composites with $\eta_{G F_{0}} \approx 0.003$. In contrast to GF-EP and GF-VE composite specimens, the matrix material VE beneficially contributes to the damping properties in the fibre direction of AF laminates. This behaviour is also observed in Fig. 11: A matrix modification of VE by 2 wt. $\%$ NC also increases the fibre dominated damping properties at $\varphi=0^{\circ}$, whereas the damping properties remain almost unchanged by a NC modification of EP. This might be explained by generally larger damping properties of VE compared to EP and differences in the matrix-fibre interface. In the off-axis fibre directions, the contribution of the AF to the damping behaviour is generally higher compared to GF. The contribution is the lowest at a fibre angle $\varphi=45^{\circ}$ due to the fibre reinforcement at $\varphi=0^{\circ}$ and $\varphi=90^{\circ}$. AF seems to be very well suited for the use in high-voltage power pylons due to its good static and dynamic mechanical properties as well as its non-conductive nature. However, other relevant parameters such as cost, increased moisture absorption and low UV resistance may hinder large scale development.

Effect of nanoclay content A matrix modification by 2 wt. \% NC was observed to be less effective for neat EP than for neat VE. ${ }^{13}$ This trend is consistent with the results presented in Fig. 11.

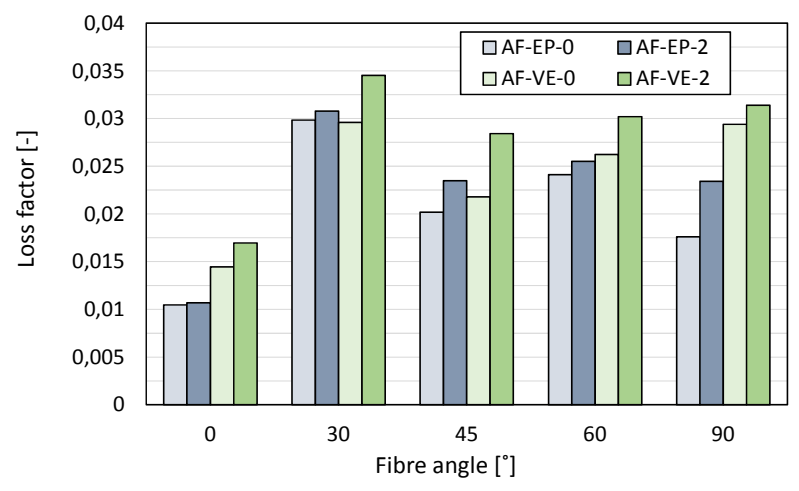

Figure 11. Effect of $\mathrm{NC}$ modification on the fibre direction dependent damping behaviour of AF-EP and AF-VE [DMTA, $0{ }^{\circ} \mathrm{C}$ at $\left.1 \mathrm{~Hz}\right]$

The small positive effect of the matrix modification on the damping is mainly observed for the off-axis directions and ranges from $+7 \%$ to $+25 \%$, depending on the matrix material and fibre direction. However, the measured damping values in the off-axis directions of AF composites are with $\eta>0.02$ significantly larger than the observed damping properties of the individual material components at temperatures at $0{ }^{\circ} \mathrm{C}$ : neat matrix material (EP-0 $(\eta=0.012)$ | EP-2 $(\eta=0.013)|\operatorname{VE}-0 \quad(\eta=0.017)| \operatorname{VE}-2 \quad(\eta=0.02))$ and $\mathrm{AF}$ in fibre direction ( $\eta<0.017$ in the fibre direction). The results are consistent with the literature ${ }^{17,31}$ and may be explained by the anisotropic material behaviour of $\mathrm{AF}$ 
and its related enhanced damping properties in off-axis directions (see Section 'Static analysis'). ${ }^{67,68}$ That effect is not observed for GF specimens, where the fibres are of isotropic nature. A matrix modification with $\mathrm{NC}$ is indeed a viable possibility for increasing the matrix dominated damping properties primarily in the off-axis directions by up to $10 \%$ to $20 \%$ for $\mathrm{AF}$ composites. However, the related restrictions with respect to manufacturability of large composite structures as well as the complex manufacturing process of $\mathrm{NC}$ modified resin need to be considered for a realistic cost-to-benefit ratio.

Effect of fibre hybridization AF and GF may together be used in hybrid-composites in order to combine their properties with respect to static and dynamic mechanical properties. ${ }^{17,69}$ Two different AF-GF-EP hybrid stacking sequences, $[\mathrm{AF}|\mathrm{GF}| \mathrm{GF}|\mathrm{GF}| \mathrm{AF}]$ and $[\mathrm{GF}|\mathrm{AF}| \mathrm{GF}|\mathrm{AF}| \mathrm{GF}]$, were investigated and compared with its non-hybrid GF-EP and AF-EP counterparts (see Fig. 12).

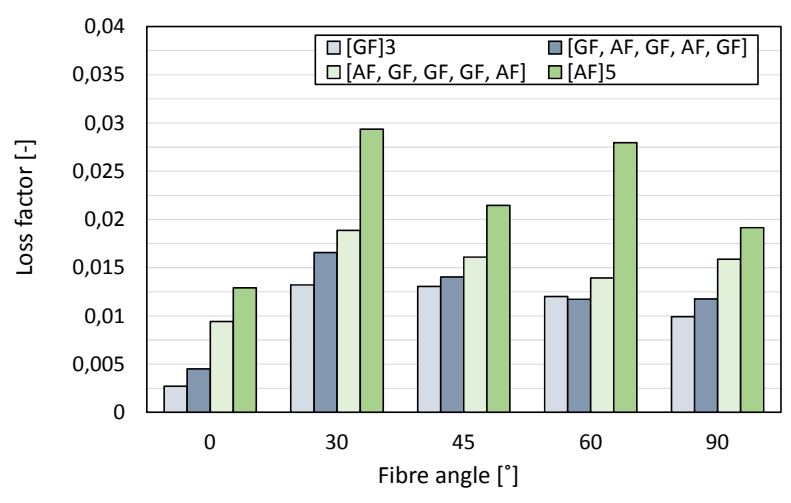

Figure 12. Effect of fibre-hybridization on the fibre direction dependent damping behaviour of GF-EP, AF-EP and AF-GF-EP [DMTA, $-20^{\circ} \mathrm{C}$ at $1 \mathrm{~Hz}$ ]

Based on the results already discussed in Section 'Effect of fibre material', GF-EP shows in general much lower damping properties compared to AF-EP. The higher the percentage of $\mathrm{AF}$ within the laminate, the higher the damping properties in all fibre directions. In case of an equal amount of AF layers within hybrid composites, its location affects the laminate damping behaviour. Laminates with $\mathrm{AF}$ layers located furthermost from the neutral axis will exhibit increased damping properties, as these layers will experience larger strains, leading to a proportionally higher damping contribution. The effect is independent of fibre orientation. The hybridization of AF and GF is an effective way to increase the damping properties of composite materials by about 20-30\% for off-axis directions and up to 3 times for the fibre direction compared to pure GF composites. However, as discussed in Section 'Effect of fibre material', further investigations related to costs and effect on different environmental conditions need to be made.

Effect of temperature The measured temperature-damping dependency of GF-EP and AF-EP in the range between $-20^{\circ} \mathrm{C}$ and $0{ }^{\circ} \mathrm{C}$ is shown in Fig. 13 .

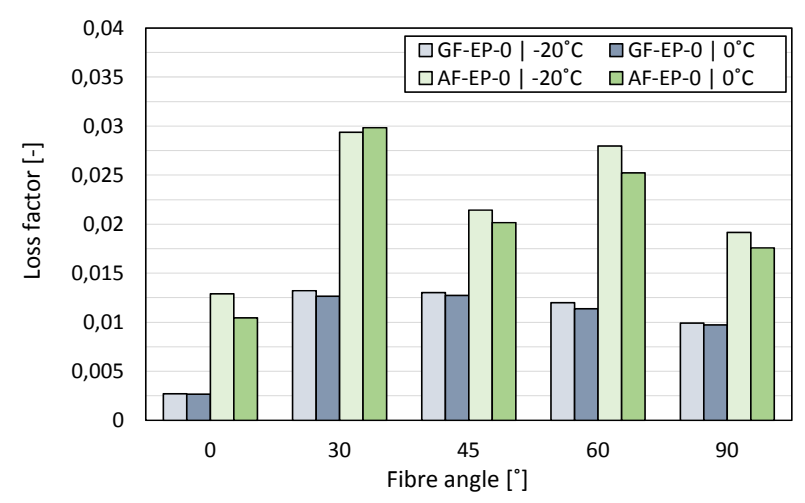

Figure 13. Effect of the testing temperature on the fibre direction dependent damping behaviour of GF-EP and AF-EP [DMTA, $-20^{\circ} \mathrm{C}$ and $0^{\circ} \mathrm{C}$ at $1 \mathrm{~Hz}$ ]

The temperature dependent damping results are consistent with the literature and a previous study on pure EP. ${ }^{13,21,49,70,71}$ An increase in temperature from $-20^{\circ} \mathrm{C}$ to $0^{\circ} \mathrm{C}$ leads to a decrease in damping for almost all AF-EP and GF-EP specimens and fibre directions. For AF-laminates, the loss factor is reduced by approximately $8 \%$ for $\varphi=45^{\circ}$ and $90^{\circ}$ as well as $20 \%$ for $\varphi=0^{\circ}$ and $60^{\circ}$, except for $\varphi=30^{\circ}$, which is a potential outlier. The decrease in damping of AF specimens in the fibre direction is in agreement with the observations made in Fig. 10 and Fig. 11 regarding the influence of matrix dominated properties in the fibre direction (see Section 'Effect of fibre material'). This effect may be explained by differences in the matrix-fibre interface compared to GF. The decrease of the damping properties of GF-EP specimens with increasing temperature is with maximum $5 \%$ negligible. However, the fibre direction dependent damping characteristics of GF-EP and AF-EP are considered constant within the temperature range relevant for galloping conductor lines.

The fibre direction damping properties $\eta_{11}, \eta_{22}$ and $\eta_{12}$ for a representative UD-layer based on the DMTA measurements and the Adams-Bacon-Approach (see Section 'Approximate damping approach') are shown in Tab.3 for all GF-composite configurations at different temperatures and NC contents.

Effect of frequency The effect of frequency on the fibre direction dependent damping is evaluated within the frequency range from $0.5 \mathrm{~Hz}$ to $2 \mathrm{~Hz}$, representative for galloping of overhead transmission lines. An increase in frequency from $0.5 \mathrm{~Hz}$ to $2 \mathrm{~Hz}$ at $-20^{\circ} \mathrm{C}$ leads to slightly 
Table 4. Calculated fibre direction dependent damping properties $\eta_{11}, \eta_{22}$ and $\eta_{12}$ based on the Adams-Bacon approach and DMTA measurements at $-20^{\circ} \mathrm{C}, 0^{\circ} \mathrm{C}$ and $20^{\circ} \mathrm{C}$ at $1 \mathrm{~Hz}$.

\begin{tabular}{ccccccccccc}
\hline \multirow{2}{*}{ Material } & \multirow{4}{*}{ wt. \% NC } & \multicolumn{3}{c}{$-20{ }^{\circ} \mathrm{C} \mid 1 \mathrm{~Hz}$} & \multicolumn{3}{c}{$0{ }^{\circ} \mathrm{C} \mid 1 \mathrm{~Hz}$} & \multicolumn{3}{c}{$20{ }^{\circ} \mathrm{C} \mid 1 \mathrm{~Hz}$} \\
& & $\eta_{11}[-]$ & $\eta_{22}[-]$ & $\eta_{12}[-]$ & $\eta_{11}[-]$ & $\eta_{22}[-]$ & $\eta_{12}[-]$ & $\eta_{11}[-]$ & $\eta_{22}[-]$ & $\eta_{12}[-]$ \\
\hline \multirow{2}{*}{ GF-EP } & 0 & 0.0028 & 0.0097 & 0.0150 & 0.0027 & 0.0095 & 0.0145 & 0.0033 & 0.0120 & 0.0186 \\
& 2 & 0.0039 & 0.0086 & 0.0159 & 0.0036 & 0.0079 & 0.0157 & 0.0038 & 0.0112 & 0.0202 \\
\multirow{2}{*}{ GF-VE } & 0 & 0.0037 & 0.0130 & 0.0174 & 0.0042 & 0.0154 & 0.0200 & 0.0048 & 0.0174 & 0.0219 \\
& 2 & 0.0039 & 0.0130 & 0.0167 & 0.0044 & 0.0161 & 0.0201 & 0.0050 & 0.0193 & 0.0230 \\
\hline
\end{tabular}

increased damping properties in fibre direction for GF-EP and AF-EP, but a decreasing loss factor in the off-axis directions with $\varphi>0^{\circ}$ (see Fig. 14).

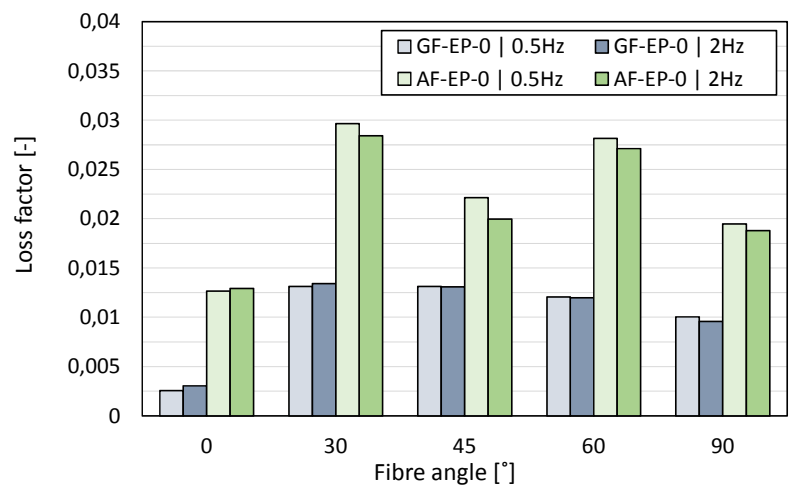

Figure 14. Effect of the testing frequency on the fibre direction dependent damping behaviour of GF-EP and AF-EP [DMTA, $-20^{\circ} \mathrm{C}$ at $0.5 \mathrm{~Hz}$ and $2 \mathrm{~Hz}$ ]

These results are in line with the literature for this particular frequency range and represent the damping behaviour dominated by fibre and matrix, respectively. ${ }^{21,72}$ Due to the negligible effect of a frequency change from $0.5 \mathrm{~Hz}$ to $2 \mathrm{~Hz}$ on the fibre direction damping, the material characterisation with regard to damping is though optimal at a representative frequency of $1 \mathrm{~Hz}$ for the design process of galloping affected composite structures.

Effect of test method The fibre direction dependent damping properties based on the two different damping measurement methods, DMTA and VBT, are analysed in this section for GF-EP and GF-VE in order to verify the comparability of the two techniques. The test parameters temperature and frequency are therefore kept equal for both tests due to the frequency and temperature dependent damping behaviour of composite materials. ${ }^{38,63,73}$ All resonant VBT measurements were carried out at $20^{\circ} \mathrm{C}$ and $20 \mathrm{~Hz}$ with an initial amplitude of $5 \mathrm{~mm}$ and $10 \mathrm{~mm}$, the nonresonant DMTA was performed at $20^{\circ} \mathrm{C}$ with frequencies of up to $10 \mathrm{~Hz}$. The fibre direction dependent damping properties for $20 \mathrm{~Hz}$ were obtained by extrapolating the data with a logarithmic approximation function. The results are presented for GF-EP specimens in Fig. 15.

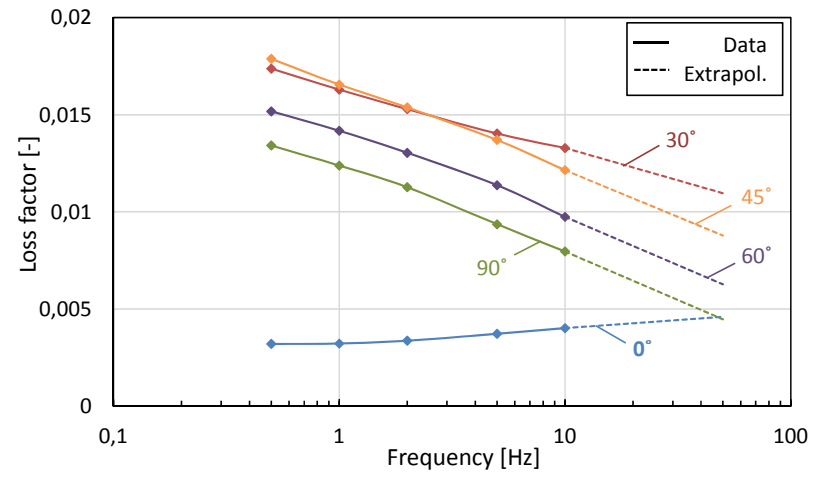

Figure 15. Frequency dependent damping properties of unbalanced GF-EP-0 [DMTA, $\left.20^{\circ} \mathrm{C}\right]$

The increase of the fibre dominated damping properties $\left(\varphi=0^{\circ}\right)$ and the decrease of the matrix dominated damping properties $\left(\varphi>0^{\circ}\right)$ with higher frequency are in line with existing DMTA results for glass and carbon fibre reinforced plastics. ${ }^{21,38}$ In contrast, damping measurements by VBT result in increasing damping with frequency for all fibre directions. ${ }^{31}$ These structural damping properties include material damping, friction damping in the clamping area and air damping, which is proportional to frequency and amplitude. ${ }^{63,74-76}$ The presence of clamping effects, influencing the overall damping behaviour, is assumed to be higher for cantilever beam configurations (VBT) with a considerably high vibration amplitude compared to simple supported beams in a three-point-bending fixture (DMTA) with vibration amplitudes of $150 \mu \mathrm{m}$.

The fibre direction dependent damping properties of GF-EP are shown in Fig. 16 for $20 \mathrm{~Hz}$ with respect to the two test methods and boundary conditions.

The DMTA results show the characteristic behaviour with its maximum at $\varphi=30^{\circ}$, although the decrease in damping at $\varphi=60^{\circ}$ and $90^{\circ}$ is unusually high (compare to Fig. 14). This behaviour may be explained by inaccurately extrapolated data. In contrast, the damping results obtained by VBT measurements increase towards $\varphi=45^{\circ}$, followed by constant damping properties for the remaining fibre angles $\varphi \geq 45^{\circ}$. This behaviour is identical to existing VBT results. ${ }^{31}$ However, it is unexpected that the damping 


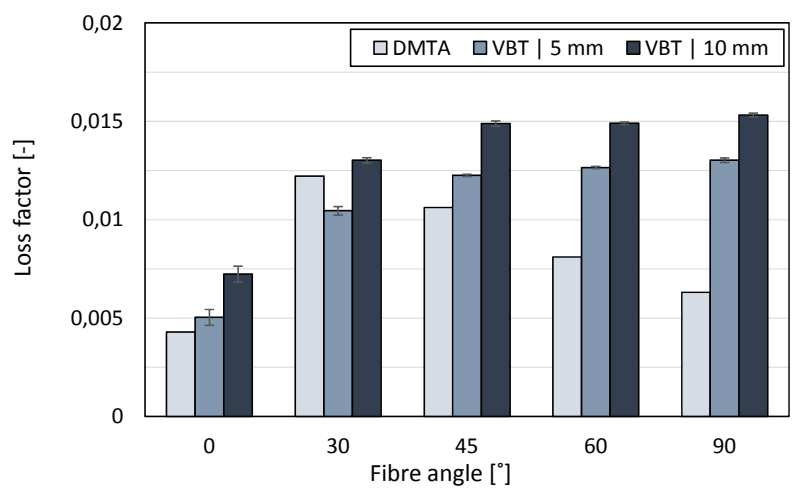

Figure 16. Effect of the test method (DMTA vs. VBT) on the fibre direction dependent damping behaviour of GF-EP at $20^{\circ} \mathrm{C}$ at $20 \mathrm{~Hz}$.

properties, obtained by VBT and DMTA, do not show similar effects or tendencies, as free-flexure conditions with an unrestricted twist are present in both test methods. Although twist-coupling effects are linked to off-axis laminates, they may contribute differently to the overall damping, depending on varying loading conditions, sample geometries and boundary condition of different test methods. The same tendency of fibre direction dependent damping for GF-EP laminates is observed for GF-VE specimens, tested by VBT and DMTA, using extrapolated data (Fig. 17).

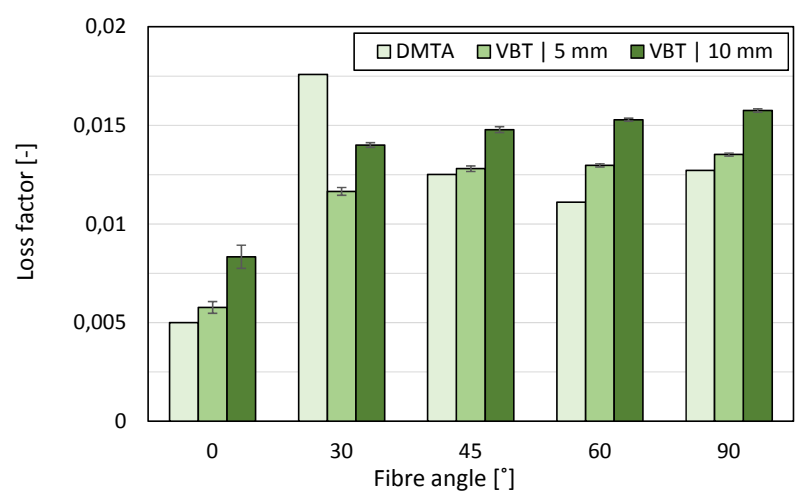

Figure 17. Effect of the test method (DMTA vs. VBT) on the fibre direction dependent damping behaviour of GF-VE at $20^{\circ} \mathrm{C}$ at $20 \mathrm{~Hz}$.

The differences in damping due to the different matrix materials VE and EP (compare Fig. 16 and Fig. 17) vary up to $30 \%$ in $\varphi=30^{\circ}$ and up to $50 \%$ in $\varphi=90^{\circ}$ for DMTA measurements, but remain almost constant in the VBT analysis. Thus, the DMTA damping measurements seem to be much more sensitive and may be better suited for analysing different material compositions, temperature and frequency dependencies as well as bend-twist-coupling effects with respect to the damping properties, compared to the resonant VBT method with its larger sample dimensions and vibration amplitudes as well as clamping influence (see Tab. 1). Furthermore, the increase of initial tip displacement from $5 \mathrm{~mm}$ to $10 \mathrm{~mm}$ leads to a constant increase of the damping properties of approximately $20 \%$ for both materials due to additional clamping effects and air damping (see Fig. 16). In order to reduce these effects, an initial tip displacement of $2.5 \mathrm{~mm}$ was investigated. Although the initial displacement may have slightly reduced the influence of air damping even further, the increasing noise in the time-displacement signal from the laser sensor resulted in deviations related to the curve fitting process. The VBT reference damping properties were therefore chosen based on the initial displacement of $5 \mathrm{~mm}$. The generally lower damping properties obtained by DMTA measurements (except for $\varphi=30^{\circ}$ due to the bend-twistcoupling effects) can mainly be related to material damping, whereas the damping measurements by VBT consist of material damping, air damping and friction damping and are therefore considered as structural damping. These significant differences between DMTA and VBT with respect to the resulting damping properties should be taken into account when using the data for the dynamic design of composite structures. ${ }^{63}$

Effect of stacking sequence All samples used for the damping characterisation by DMTA and VBT had a symmetric and unbalanced laminate architecture in order to fulfil the Adams-Bacon-Approach (see Fig. 1). ${ }^{37}$ Therefore, the damping results obtained by DMTA measurements showed distinct peaks at a fibre angle of $\varphi \approx 30^{\circ}$ due to bend-twist coupling effects, linked to off-axis laminates (see Fig. 11 and Fig. 13). ${ }^{36}$ This additional damping will artificially overestimate the shear damping property $\eta_{12}$ of a representative UD layer, from which symmetric, balanced and bend-twist-coupling-free multilayer composite structures are modelled. In order to prevent this systematic error, the coupling related damping needs to be evaluated and quantified. Therefore, the contribution of the coupling effects on the direction dependent damping properties are investigated for GF-EP and GF-VE by comparing the damping behaviour of unbalanced and balanced laminates, where the latter should be unaffected by bend-twisting effects. The damping results of GF-EP with balanced and unbalanced stacking sequences are shown in Fig. 18 based on DMTA and VBT measurements at $20^{\circ} \mathrm{C}$ and $20 \mathrm{~Hz}$.

No distinction between balanced and unbalanced stacking sequences is made in the fibre directions $\varphi=0^{\circ}$ and $\varphi=90^{\circ}$, as only balanced laminates will meet these conditions. According to Fig. 18 and observations made in Section 'Effect of test method', no peaks at a fibre angle 


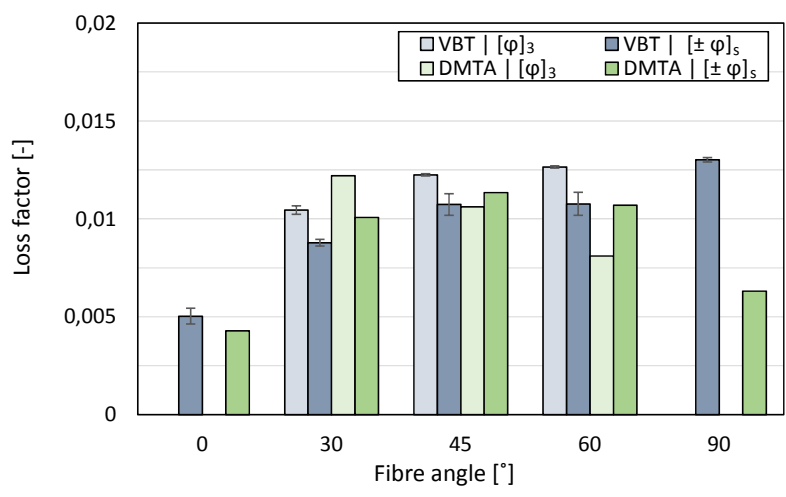

Figure 18. Effect of the stacking sequence (unbalanced $[\varphi]_{3}$ vs. balanced $[ \pm \varphi]_{s}$ ) on the fibre direction dependent damping behaviour of GF-EP [DMTA, VBT $(5 \mathrm{~mm}), 20^{\circ} \mathrm{C}$ at $20 \mathrm{~Hz}$ ]

of $\varphi \approx 30^{\circ}$ occur for VBT measurements from specimens with balanced and unbalanced stacking sequence. Instead, the damping increases constantly up to a fibre angle of $\varphi \approx 45^{\circ}$, followed by a slight increase up to a fibre angle of $\varphi=90^{\circ}$. This trend indicates that existing bend-twist coupling effects are superimposed by air damping, friction damping in the clamping zone and other effects. Thus, an assessment of bend-twist coupling effects can not be made by VBT measurements. Furthermore, the specimens with a balanced layup show about $15 \%$ lower damping properties for $30^{\circ}<\varphi<60^{\circ}$ compared to specimens with an unbalanced layup. This may also be explained by differences in the specimen thickness, resulting in a change in stiffness and air damping contribution. Specimens with an unbalanced stack were $25 \%$ thinner compared to specimens with a balanced stack (see Tab. 1 and Fig. 1). On the other hand, the vibrating length, and therefore the area affected by air damping, were reduced for unbalanced laminates in order to keep the vibration frequency constant at $f_{1}=20 \mathrm{~Hz}$.

Damping results obtained by DMTA measurements of laminates with an unbalanced stack, exhibit a peak related to coupling effects at $\varphi \approx 30^{\circ}$. In accordance to the findings above, the highest damping for balanced GFEP laminates is observed for $\varphi= \pm 45^{\circ}$. This damping characteristics without bend-twist coupling effects is expected, as shear stresses attain their maximum for this particular stacking sequence. The introduction of an equivalent shear damping $\eta_{12_{e q}}$ for the DMTA damping analysis of balanced laminates may therefore underestimate the damping behaviour of a representative UD-layer: BD laminates with balanced stacking sequences show higher tensile moduli for $\varphi= \pm 30^{\circ}, \pm 45^{\circ}$ and $\pm 60^{\circ}$ compared to unbalanced UD laminates, resulting in higher in-plane shear stiffness and thus a reduced equivalent shear damping $\eta_{12_{e q}}$ (see Fig. 19).

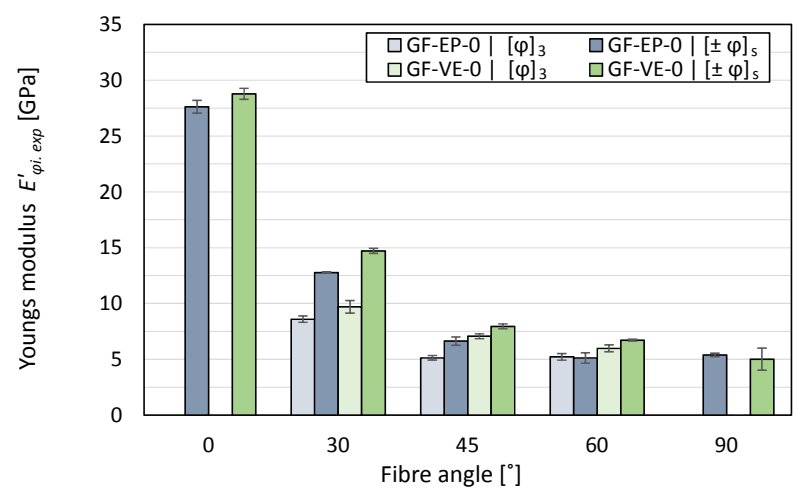

Figure 19. Effect of the stacking (unbalanced $[\varphi]_{3}$ Vs. balanced $[ \pm \varphi]_{s}$ ) on the fibre direction dependent Youngs modulus of GF-EP and GF-VE.

The calculated shear damping $\eta_{12}$ (for unbalanced laminate) and the equivalent shear damping $\eta_{12_{e q}}$ (for balanced laminate) based on Eq. (5) and (6) may result only in small variations: the damping in $\varphi=30^{\circ}$ is approx. $20 \%$ higher for unbalanced laminates, whereas balanced laminates show approx. $20 \%$ higher damping in $\varphi=60^{\circ}$ (see Fig. 18). Furthermore, the damping properties in $\varphi=45^{\circ}$ are in the same range. Thus, the apparent differences in damping for $\varphi=30^{\circ}$ and $\varphi=60^{\circ}$ may simply cancel out.

Finally, the differences in damping between balanced and unbalanced laminates are less than expected and may not significantly influence the shear damping properties of the investigated materials.

\section{Comparison of numerical and experimental damping analysis}

In order to verify the experimentally determined static and dynamic mechanical properties, the first natural frequency $f_{1}$ and the related modal damping $\eta$ of a vibrating multilayer composite beam were predicted by a finite element analysis (FEA). Four different input parameter sets with respect to the modal damping were used to simulate the VBT test procedure at room temperature for three GF-EP-0 specimens with $[+30,-30]_{s},[+45,-45]_{s}$ and $[+60,-60]_{s}$, based on the variation of the test method and a balanced or unbalanced stacking sequence: 1. - unbalanced, DMTA | 2. - balanced, DMTA | 3.- unbalanced, VBT | 4.- balanced, VBT. The results of the numerical analysis are listed in Tab 5. Furthermore, a mesh convergence study based on the input parameter set '4. - balanced, VBT' is presented in Fig. 20.

The number of elements used for the numerical simulation was set to $\mathrm{n}_{e l}=680$. A sufficient mesh refinement was thereby verified. The prediction of the first natural frequency 
Table 5. Experimental and FEA-results of a vibrating cantilever GF-composite sample with regard to different damping property input scenarios.

\begin{tabular}{|c|c|c|c|c|c|c|c|c|}
\hline Material & Stack & $\begin{array}{c}\text { Free } \\
\text { Length }[\mathrm{mm}]\end{array}$ & Parameter & $\begin{array}{c}\text { VBT } \\
\text { Experiment }\end{array}$ & $\begin{array}{l}\text { FEA (based or } \\
\text { u.bal| DMTA }\end{array}$ & $\begin{array}{r}\text { four different } \\
\text { bal|DMTA }\end{array}$ & $\begin{array}{c}\text { amping input } \\
\text { u.bal|VBT }\end{array}$ & $\begin{array}{c}\text { rameter sets } \\
\text { bal|VBT }\end{array}$ \\
\hline \multirow{4}{*}{ GF-EP-0 } & {$[+30,-30]_{s}$} & 195.9 & $\begin{array}{c}f_{1}[\mathrm{~Hz}] \\
\eta[-] \\
\Delta \eta[\%]\end{array}$ & $\begin{array}{c}19.90 \\
0.0089 \\
(0.0002)\end{array}$ & $\begin{array}{c}0.009 \\
(0.9)\end{array}$ & $\begin{array}{c}21.45(\Delta \\
0.0087 \\
(2.2)\end{array}$ & $\begin{array}{c}1=7.8 \%) \\
0.0087 \\
(2.8)\end{array}$ & $\begin{array}{c}0.0074 \\
(16.4)\end{array}$ \\
\hline & {$[+45,-45]_{s}$} & 179.1 & $\begin{array}{c}f_{1}[\mathrm{~Hz}] \\
\eta[-] \\
\Delta \eta[\%]\end{array}$ & $\begin{array}{c}20.07 \\
0.0112 \\
(0.0001)\end{array}$ & $\begin{array}{c}0.0108 \\
(3.5)\end{array}$ & $\begin{array}{c}19.59(\Delta \\
0.0107 \\
(4.9)\end{array}$ & $\begin{array}{c}1=2.4 \%) \\
0.0109 \\
(2.9)\end{array}$ & $\begin{array}{c}0.00918 \\
(18.0)\end{array}$ \\
\hline & {$[+60,-60]_{s}$} & 169.1 & $\begin{array}{c}f_{1}[\mathrm{~Hz}] \\
\eta[-] \\
\Delta \eta[\%]\end{array}$ & $\begin{array}{c}20.35 \\
0.0113 \\
(0.0001)\end{array}$ & $\begin{array}{c}0.0092 \\
(18.8)\end{array}$ & $\begin{array}{l}19.77(\Delta \\
0.0096 \\
(15.1)\end{array}$ & $\begin{array}{c}1=2.9 \%) \\
0.0123 \\
(9.2)\end{array}$ & $\begin{array}{c}0.0111 \\
(1.7)\end{array}$ \\
\hline & & & & Mean $\Delta \eta[\%]$ & (7.7) & (7.4) & $(5.0)$ & $(12.1))$ \\
\hline
\end{tabular}

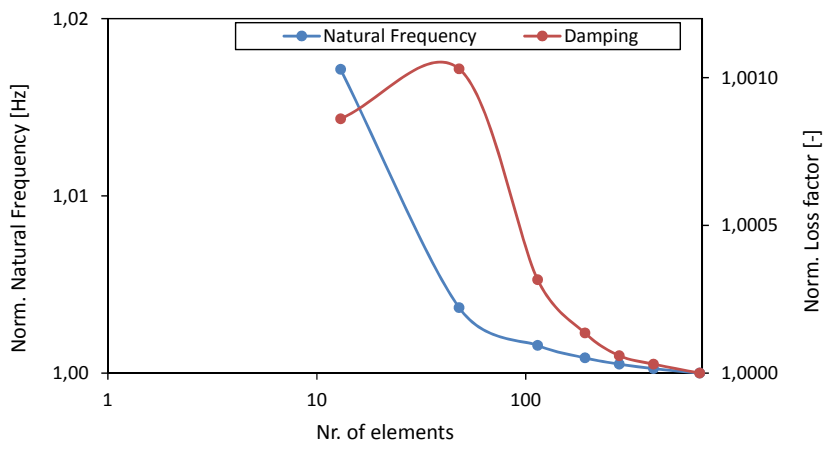

Figure 20. Mesh convergence study of the numerical model with regard to the normalized loss factor and normalized natural frequency.

$f_{1}$ for GF-EP-0 specimens with a stack of $[+30,-30]_{s}$ is with a relative deviation of $7.8 \%$ slightly overestimated. As no manufacturing imperfections were considered in the simulation, a slight misalignment in the specimens fibre orientation at $\varphi=30^{\circ}$ may explain the reduced natural frequency measured by VBT. A clearly more accurate prediction for laminates with a stack of $[+45,-45]_{s}$ and $[+60,-60]_{s}$ was achieved with a relative deviation of maximal $2.9 \%$, both slightly under-predicting $f_{1}$.

It is expected that numerical simulations based on VBTrelated damping properties over-predict the modal loss factor, as several damping sources such as material damping, friction damping in the clamping area and air damping as an external damping source are included. In contrast, neither friction damping nor air damping are considered in the numerical model. In fact, this assumption has not been borne out by the simulations based on VBT-measurements of laminates with an unbalanced stack. The predicted modal damping is very close to the experimental values and an overprediction is only observed for specimens with a $[+60,-60]_{s}$ stack. In contrast, the prediction of the modal damping based on VBT measurements of laminates with a balanced stack lead to high deviations and will therefore not be discussed any further.

Moreover, damping predictions based on DMTA-related damping properties were assumed to result in more precise results, as only material damping is considered in the numerical model. Indeed, a good damping prediction is observed for $[+30,-30]_{s}$ and $[+45,-45]_{s}$ with a relative deviation of max. $4.9 \%$, but the calculated modal loss factor for $[+60,-60]_{s}$ is under-predicted by a maximum of $18.8 \%$. This discrepancy for larger fibre angles $\left(\varphi \geq 60^{\circ}\right)$ may be related to an added inaccuracy by the applied extrapolation. The drop in damping for $\varphi=60^{\circ}$ and $90^{\circ}$ is considered unusually high (see Fig. 16), as mentioned in section 'Effect of test method'.

In contrast, the VBT-related damping properties are constant for $\varphi \geq 45^{\circ}$ (see Fig. 16), whereby they are slightly overpredicted by $9.2 \%$ for the $[+60,-60]_{s}$ specimens. It is assumed that the 'correct' damping for GF-EP-0 at $\varphi \geq 60^{\circ}$ is mean value of the VBT and DMTA results.

As expected, only small variations between DMTA-related damping properties with unbalanced and balanced stacking sequences are observed. The difference in loss factor at $\varphi=30^{\circ}$ and $\varphi=60^{\circ}$ are similar (see Fig. 18) and will therefore cancel each other out, when calculating the shear damping $\eta_{12}$ based on Eq. (5) and Eq. (6). The damping prediction for laminates with stacking sequences at large fibre angles $[+60,-60]_{s}$ is equally inaccurate for both DMTA-related damping input parameter sets. However, for both unbalanced and balanced stacking sequences, a good damping prediction is obtained for laminates with fibre angles $\varphi<60^{\circ}$ based on DMTA measurements. The concerns with regard to bend-twist-coupling related deviations for the simulations are therefore seemingly 
unfounded. Other effects like friction damping due to clamping may have much higher impact on the modal loss factor.

In fact, the most accurate prediction with $\Delta \eta=5.0 \%$ for all stacking sequences $[+30,-30]_{s},[+45,-45]_{s}$ and $[+60,-60]_{s}$ is based on the VBT-related damping properties with an unbalanced stack. This may be explained by the similarity of the experiment and the numerical model in terms of specimen geometry, boundary condition and the related stress distribution. Thus, VBT-related damping measurements of laminates with an unbalanced stack will further be used to predict the modal damping of more complex composite structures.

\section{Conclusion}

The characterisation and prediction of damping properties for non-conductive composite materials such as aramid and glass fibre reinforced plastics have been presented. The direction dependent damping properties have been evaluated under environmental conditions prone for the galloping phenomena, considering different material modifications such as the addition of nanoclay fillers, the variation of matrix materials and the hybridization of glass and aramid fibres. Furthermore, the modal damping was successfully predicted for laminates with different stacking sequences based on damping properties obtained by VBT and DMTA measurements. The main conclusions are as follows:

- AF composites showed up to four times higher damping at $-20^{\circ} \mathrm{C}$ compared to GF composites.

- At $0{ }^{\circ} \mathrm{C}$ approximately $30 \%$ higher damping was obtained for the matrix material VE compared to EP.

- Nanoclay led to an increase in the off-axis damping for AF by 10 to $20 \%$ at $0{ }^{\circ} \mathrm{C}$.

- A fibre hybridization of GF and AF may enhance the damping in the fibre direction by $300 \%$ and in the offaxis direction by $20-30 \%$ at $-20^{\circ} \mathrm{C}$.

- The direction dependent damping of GF and AF composites are frequency and temperature dependent. However, at environmental conditions close to galloping, only small changes were observed.

- Damping measurements by DMTA seem to be more sensitive to changes in the stacking sequence.

- The predicted natural frequency and modal damping are in good accordance to the experimental results. The damping properties based on VBT measurements for unbalanced laminates showed the best match.

The latter point raises the question, which damping measurement method to chose for predicting the modal damping of a structure. This may depend primarily on the boundary conditions, due to their substantial influence on the damping. In case of a free-free-boundary condition, no clamping effects will occur and therefore damping values obtained by DMTA measurements may fit well. On the other hand, a free vibrating structure under a clamped-free condition will experience friction damping in the clamping zone. Therefore, damping properties obtained by VBT may better represent the damping behaviour. However, the quality of the clamping is a governing factor of the damping measurements, which must be taken into consideration in each individual case.

In future work, the obtained damping parameters will be applied to more complex composite structures in order to evaluate their modal damping. Therefore, the influence of the clamping effects on the overall damping has to be carefully evaluated. Furthermore, passive and non-conductive constrained layer damping treatments are very promising for the use in high-voltage power pylons. The damping may thereby significantly be increased by viscoelastic intermediate layers, when subjected to shear. The related trade-off between a reduction in natural frequency and an increase in damping and weight may then be investigated using optimization algorithms. However, the design criteria weight will thereby only be of minor importance, as the power pylon is considered mainly as a static structure.

\section{Acknowledgement}

Thanks to Prof. M. Gude and Prof. N. Modler from the Institute of Lightweight Engineering and Polymer Technology at TU Dresden for their kind cooperation in carrying out the experimental dynamic study of this work. The 3D Imaging Centre at The Technical University of Denmark is also gratefully acknowledged for their valuable support on image processing.

\section{Declaration of conflicting interests}

The author(s) declared no potential conflicts of interest with respect to the research, authorship and/or publication of this article.

\section{Funding}

The author(s) disclosed receipt of the following financial support for the research, authorship and/or publication of this article: This research is supported by Innovationsfonden Denmark via the project Power Pylons of the Future 
(PoPyFu) in collaboration with Bystrup and Tuco Marine ApS, which are gratefully acknowledged.

\section{References}

1. European Network of Transmission System Operators for Electricity (2012) Ten-Year Network Development Plan 2012. www.entsoe.eu.

2. Guedes AV, Matt CF, Cavalcanti ESC (2005) Experimental investigation of the dynamic behaviour of stockbridge dampers. 18th International Congress of Mechanical Engineering November 6-11, 2005, Ouro Preto, MG.

3. Macdonald JHG, Larose GL (2008) Two-degree-of-freedom inclined cable gallopingPart 1: General formulation and solution for perfectly tuned system. J. Wind Eng. Ind. Aerodyn. 96: 291-307.

4. Macdonald JHG, Larose GL (2008) Two-degree-of-freedom inclined cable gallopingPart 2: Analysis and prevention for arbitrary frequency ratio. J. Wind Eng. Ind. Aerodyn. 96: 308326.

5. Hu J, Yan B, Zhou S, et al. (2010) Parameter Study on Galloping of Iced Bundled Conductors. Power and Energy Engineering Conference (APPEEC), 2010 Asia-Pacific, IEEE.

6. Lilien JL (2007) State of the art of conductor galloping. Electra Technical Brochure 322.

7. Svensson, H (2013) Cable-Stayed Bridges: 40 Years of Experience Worldwide. Wilhelm Ernst und Sohn, Verlag fr Architektur und technische Wissenschaften GmbH und Co. KG.

8. Hu N (2012) Composites and Their Properties. InTech- Open access DOI: 10.5772/2816.

9. Ibrahimbegovic A, Kozar I (2007) Extreme Man-Made and Natural Hazards in Dynamics of Structures. Springer, NATO Security through Science Series.

10. Li SY, Chen ZQ (2009) Experimental investigation concerning aerodynamic stability of a stay cable incorporated with lamps. The Seventh Asia - Pacific Conference on Wind Engineering, November 8-12, 2009, Taipei, Taiwan.

11. Treviso A, Van Genechten B, Mundo D, Tournour M (2015) Damping in Composite Materials: Properties and Models. Composites Part B doi: 10.1016/j.compositesb.2015.03.081.

12. Cremer L, Heckl M (1988) Structure-borne sound: structural vibrations and sound radiation at audio frequencies. SpringerVerlag, Berlin.

13. Kliem M, Høgsberg J, Wang Q, Dannemann M (2017) Characterization of clay-modified thermoset polymers under various environmental conditions for the use in high-voltage power pylons. Advances in Mechanical Engineering 9: 1-16.

14. Bertolino V, Cavallaro G, Lazzara G, Merli M, Milioto S, Parisi F, Sciascia L (2016) Effect of the Biopolymer Charge and the Nanoclay Morphology on Nanocomposite Materials. Industrial and Engineering Chemistry Research 55: 7373-7380.

15. Makaremi M, Pasbakhsh P, Cavallaro G, Lazzara G, Aw YK, Lee SM, Milioto S (2017) Effect of Morphology and Size of Halloysite Nanotubes on Functional Pectin Bionanocomposites for Food Packaging Applications. Applied Materials and Interfaces 9: 17476-17488.
16. Agubra VA, Owuor PS, Hosur MV (2013) Influence of Nanoclay Dispersion Methods on the Mechanical Behavior of E-Glass/Epoxy Nanocomposites. Nanomaterials 3: 550-563.

17. Bulut M, Erklig A, Yeter E (2015) Experimental investigation on influence of Kevlar fiber hybridization on tensile and damping response of Kevlar/glass/epoxy resin composite laminates. Journal of Composite Materials 50: 1875-1886.

18. Berthelot JM, Assarar M, Sefrani Y, Mahi Y (2008) Damping analysis of composite materials and structures. Compos. Struct. 85: 189-204.

19. Sefrani Y, Berthelot JM (2006) Temperature effect on the damping properties of unidirectional glass fibre composites. Composites: Part B 37: 346-355.

20. Colakoglu M (2008) Effect of Temperature on Frequency and Damping Properties of Polymer Matrix Composites. Adv. Compos. Mater. 17: 111-124.

21. Li J, Sun B, Du Y (2012) Damping Properties of Fiber Reinforced Composite Suitable for Stayed Cable. Third International Conference on Smart Materials and Nanotechnology in Engineering 11-13 November 2011, Shenzhen, China.

22. Zhang HZ, Chen HL (2006) A study on the damping characteristics of laminated composites with integral viscoelastic layers. Composite Structures 74: 63-69.

23. Dannemann M (2012) Zur vibroakustischen Auslegung von Faserverbund-Leichtbaustrukturen. Dissertation Technische Universitaet Dresden, 2012.

24. Saravons DA, Chamis CC (1990) Unified Micromechanics of Damping for Unidirectional and Off-Axis Fiber Composites. Journal of Composites, Technology and Research 12: 31-40.

25. Holste, C (1998) Zum Daempfungsverhalten anisotroper Faserverbundstrukturen. Dissertation Technische Universitaet Clausthal, 1998.

26. Stankiewicz B (2017) Durability of glass fiber-reinforced polymer bridge panel based on differential thermal analysis, dynamic mechanical analysis, and differential scanning calorimetry analysis. Journal of composite materials 51: 23012313.

27. Pothan LA, Potschke P, Habler R, Thomas S (2005) The Static and Dynamic Mechanical Properties of Banana and Glass Fiber Woven Fabric-Reinforced Polyester Composite. Journal of composite materials 39: 1007-1025.

28. Fotsing ER, Sola M, Ross A, Ruiz E (2012) Lightweight damping of composite sandwich beams: Experimental analysis. Journal of composite materials 47: 1501-1511.

29. Huang CH, Tsai JL (2015) Characterizing vibration damping response of composite laminates containing silica nanoparticles and rubber particles. Journal of composite materials 49: 545-557.

30. Chortis, DI (2013) Structural Analysis of Composite Wind Turbine Blades - Nonlinear Mechanics and Finite Element Models with Material Damping. Springer-Verlag, Berlin.

31. Berthelot JM, Sefrani Y (2004) Damping analysis of unidirectional glass and Kevlar fibre composites. Composites Science and Technology 64: 1261-1278. 
32. Landel RF, Nielsen LE (1993) Mechanical Properties of Polymers and Composites. CRC Press 2nd Edition.

33. Heistermann T (2013) Stiffness of reverse channel connections at room and elevated temperatures. Dissertation Luleå University of Technology, 2013.

34. Mason BH, Sleight DW, Grenoble RW (2015) Test and Analysis Correlation for a Y-Joint Specimen for a Composite Cryotank. Report, NASA Langley Research Center, NASA/TM2015-218967, 2015.

35. Brown J (1997) Characterization of MSC/NASTRAN and MSC/ABAQUS Elements for Turbine Engine Blade Frequency Analysis. Proceedings of the MSC Aerospace User Conference 1997.

36. Hwang SJ, Gibson RF (1993) Influence of bending-twisting and extension-bending coupling on damping of laminated composites. Journal of Materials Science 28: 1-8.

37. Adams RD, Bacon DGC (1973) Effect of Fibre Orientation and Laminate Geometry on the Dynamic Properties of CFRP. Journal of Composite Materials 7: 402-428.

38. Melo JDD, Radford DW (2005) Time and temperature dependence of the viscoelastic properties of CFRP by dynamic mechanical analysis. Composite Structures 70: 240-253.

39. Jaroschek C (2012) The end of the flexural modulus. Journal of Plastics Technology 8: 515-524

40. DIN EN ISO 178 (2011) Plastics - Determination of flexural properties. German Institute for Standardisation

41. Altenbach H, Altenbach J, Kissing W (2004) Mechanics of Composite Structural Elements. Springer-Verlag, Berlin.

42. Staab, G (2015) Laminar Composites. 2nd Edition Butterworth-Heinemann.

43. Li H, Hu Z, Chandrashekhara K, Du X, Mishra R (2013) Reliability-based fatigue life investigation for a medium-scale composite hydrokinetic turbine blade. Ocean Engineering 89: 230-242.

44. Samborsky DD, Mandell JF, Agastra P (2013) 3-D Static Elastic Constants and Strength Properties of a Glass/Epoxy Unidirectional Laminate. Technical Report Chemical and Biological Engineering Department, Composite Technologies Research Group, Montana State University.

45. Carfagni M, Lenzi E, Pierini M (1998) The Loss Factor as a Measure of Mechanical Damping. Proceedings - The International Society for Optical Engineering Jan.98.

46. Duc F, Bourban PE, Manson JAE (2014) The role of twist and crimp on the vibration behaviour of flax fibre composites. Composites Science and Technology 102: 94-99.

47. ABAQUS (2017) ABAQUS Documentation. Dassault Systmes Providence, RI, USA.

48. Ungar EE, Kerwin M (1962) Loss factors of viscoelastic systems in terms of energy concepts. The Journal of the Acoustical Society of America 34: 954.

49. Zhang PQ, Ruan JH, Li WZ (2001) Influence of some factors on the damping property of fiber-reinforced epoxy composites at low temperature. Cryogenics 41: 245-251.

50. Kliem M (2017) Experimental data for analysing the damping behaviour of non-conductive composite materials. Mendeley Data doi:10.17632/65t5zzxvm5.1
51. Messiry ME (2013) Theoretical analysis of natural fiber volume fraction of reinforced composites. Alexandria Engineering Journal 52: 301-306.

52. DIN EN 2331 (1993) Prüfmethode zur Bestimmung des Harzund Faseranteils sowie der flächenbezogenen Fasermasse. Normenstelle Luftfahrt (NL) im DIN Deutsches Institut für Normung e. $V$.

53. Schürmann H (2007) Konstruieren mit Faser-KunststoffVerbunden. Springer-Verlag, Berlin Heidelberg

54. Yi K, Geng D, Shang C, He Y, Yang J (2015) The application of thermogravimetric analysis method in the determination of aramid fiber content in composite. 10th International Conference on Composite Science and Technology February 2015, Lisbon, Portugal.

55. ASTM D3039 (2014) Test Method for Tensile Properties of Polymer Matrix Composite Materials. ASTM International

56. Melo JDD, Radford DW (2003) Viscoelastic Characterization of Transversely Isotropic Composite Laminae. Journal of Composite Materials 37: 129-145.

57. Cogswell FN (1998) Polymer Melt Rheology: A Guide for Industrial Practice. Woodhead Publishing Ltd 1st edition.

58. Kelly, SG (2011) Mechanical Vibrations: Theory and Applications. Cengage Learning, 1st edition.

59. Assarar M, El Mahi A, Berthelot JM (2009) Damping Analysis of Sandwich Composite Materials. Journal of Composite Materials 43: 1461-1485.

60. Guan H, Gibson RF (2001) Micromechanical Models for Damping in Woven Fabric-Reinforced Polymer Matrix Composites. Journal of Composite Materials 35: 1417-1434.

61. Vanwalleghem J, Baere ID, Loccufier M, Paepegem WV (2012) Practical aspects in measuring vibration damping of isotropic materials. Proceedings - 15th International Conference on Experimental Mechanics July 2012, Porto, Portugal.

62. Borbon FD, Ambrosini D, Curadelli O (2013) Damping response of composites beams with carbon nanotubes. Composites: Part B 60: 106-110.

63. Rueppel M, Rion J, Dransfeld C, Fischer C, Masania K (2017) Damping of carbon fibre and flax fibre angle-ply composite laminates. Composites Science and Technology 146: 1-9.

64. Kiral Z, Malgaca L, Akdag M, Kiral BG (2009) Experimental Investigation of the Dynamic Response of a Symmetric Laminated Composite Beam Via Laser Vibrometry. Journal of Composite Materials 43: 2943-2962.

65. Beards CF (1996) Engineering Vibration Analysis with Application to Control Systems. Wiley - Technology and Engineering, 1st edition.

66. Petersen HN, Kusano Y, Brondsted P, Almdal K (2016) The influence of removing sizing on strength and stiffness of conventional and high modulus E-glass fibres. IOP Conf. Ser.: Mater. Sci. Eng. 139012040.

67. Herakovich, CT (1997) Mechanics of Fibrous Composites. Wiley, 1st edition.

68. Wollbrett-Blitz J, Joannes S, Bruant R, Le Clerc C, Romero De La Osa M, Bunsell A, Marcellan A (2015) Multiaxial Mechanical Behavior of Aramid Fibers and 
Identification of Skin/Core Structure from Single Fiber Transverse Compression Testing. Journal of Polymer Science. Part B DOI: 10.1002/polb.23763.

69. Sandesh KJ, Umashankar KS, Manujesh BJ, Thejesh CK, Mohan Kumar NM (2016) Mechanical Charaterisation of Kevlar/Glass Hybrid Reinforced Polymer composite laminates. International Advanced Research Journal in Science, Engineering and Technology DOI 10.17148/IARJSET.2016.31218

70. Margem FM, Monteiro SN, Neto JB, Rodriguez RJS, Soares BG (2010) The dynamic-mechanical behavior of epoxy matrix composites reinforced with ramie fibers. Revista Matria 15: 164-171.

71. Jensen RE, McKnight SH, Palmese GR (2003) Viscoelastic Properties of Alkoxy Silane-Epoxy Interpenetrating Networks. Army Research Laboratory Aberdeen Proving Ground, MD 21005-5069, ARL-TR-3109.

72. Bonakdar M, Seidel GD, Inman DJ (2011) Damping characterization of viscoelastic composites using micromechanical approach. Proceedings of SPIE - The International Society for Optical Engineering DOI: 10.1117/12.880481.

73. Melo JDD, Radford DW (2005) Viscoelastic Properties of PEEKIM7 related to Temperature. Journal of Reinforced Plastics and Composites 24: 545-556.

74. Baker WE, Woolam WE, Young D (1967) Air and internal damping of thin cantilever beams. International Journal of Mechanical Sciences 9: 743-766.

75. Stephens DG, Scavullo MA (1965) Investigation of Air Damping of Cicular and Rectangular Plates, a Cylinder, and a Sphere. NASA TECHNICAL NOTE, NASA TN D-1865.

76. Bleicher A (2011) Multimodal active vibration control of a stress ribbon bridge using pneumatic muscle actuators. Dissertation Technische Universität Berlin, 2011. 